\title{
Silencing of Vlaro2 for chorismate synthase revealed that the phytopathogen Verticillium longisporum induces the cross-pathway control in the xylem
}

\author{
Seema Singh • Susanna A. Braus-Stromeyer • Christian Timpner • Van Tuan Tran • \\ Gertrud Lohaus • Michael Reusche • Jessica Knüfer • Thomas Teichmann • \\ Andreas von Tiedemann • Gerhard H. Braus
}

Received: 22 August 2009/Revised: 20 September 2009 /Accepted: 20 September 2009/Published online: 14 October 2009

(C) The Author(s) 2009. This article is published with open access at Springerlink.com

\begin{abstract}
The first leaky auxotrophic mutant for aromatic amino acids of the near-diploid fungal plant pathogen Verticillium longisporum (VL) has been generated. VL enters its host Brassica napus through the roots and colonizes the xylem vessels. The xylem contains little nutrients including low concentrations of amino acids. We isolated the gene Vlaro2 encoding chorismate synthase by complementation of the corresponding yeast mutant strain. Chorismate synthase produces the first branch point
\end{abstract}

The EMBL database accession number for the sequence of Vlaro2 reported in this paper is FM999811.

Electronic supplementary material The online version of this article (doi:10.1007/s00253-009-2269-0) contains supplementary material, which is available to authorized users.

S. Singh $\cdot$ S. A. Braus-Stromeyer $\cdot$ C. Timpner $\cdot$ V. T. Tran $\cdot$

G. H. Braus $(\bowtie)$

Institut für Mikrobiologie und Genetik, Georg-August-Universität, Grisebachstr. 8,

37077 Göttingen, Germany

e-mail: gbraus@gwdg.de

G. Lohaus

Büsgen-Institut, Georg-August-Universität,

Büsgenweg 5,

37077 Göttingen, Germany

M. Reusche $\cdot$ T. Teichmann

Albrecht-von-Haller-Institut für Pflanzenwissenschaften,

Georg-August-Universität,

Untere Karspüle 2,

37073 Göttingen, Germany

J. Knüfer $\cdot$ A. von Tiedemann

Department für Nutzpflanzenwissenschaften,

Georg-August-Universität,

Grisebachstr. 6,

37077 Göttingen, Germany intermediate of aromatic amino acid biosynthesis. A novel RNA-mediated gene silencing method reduced gene expression of both isogenes by $80 \%$ and resulted in a bradytrophic mutant, which is a leaky auxotroph due to impaired expression of chorismate synthase. In contrast to the wild type, silencing resulted in increased expression of the cross-pathway regulatory gene VlcpcA (similar to $c p c A$ / $G C N 4)$ during saprotrophic life. The mutant fungus is still able to infect the host plant $B$. napus and the model Arabidopsis thaliana with reduced efficiency. VlcpcA expression is increased in planta in the mutant and the wild-type fungus. We assume that xylem colonization requires induction of the cross-pathway control, presumably because the fungus has to overcome imbalanced amino acid supply in the xylem.

Keywords Chorismate synthase $\cdot$ RNA silencing · Verticillium wilt · Amino acid metabolism · Cross-pathway control

\section{Introduction}

Natural energy resources are limited, and there is an increasing demand for biofuel to counteract this limitation. This resulted in the past decades in mass plantation of numerous plants including maize, oil palm, sweet sorghum, or rapeseed. The demand for rapeseed oil is rising as it is a healthy vegetable oil and also a renewable resource for the oleochemical industry and the biodiesel production. The dark side of this development is the appearance of unknown and may be even novel specific plant pathogens like Verticillium longisporum, a devastating vascular pathogen of rapeseed Brassica napus (Karapapa et al. 1997). 
V. longisporum is a soil-borne hemibiotroph and opportunistic phytopathogen, which infects through the roots, colonizes the rapeseed plant, and then produces microsclerotia in the necrotrophic stage (Zhou et al. 2006; Eynck et al. 2007). $V$. longisporum can also live saprotrophically and survive in the soil. Microsclerotia of $V$. longisporum are present in the soil and persist there for many years in this dormant form (Schnathorst 1981; Heale and Karapapa 1999). V. longisporum infects through the root surface by direct penetration of the epidermal cells in the root hair zone (Eynck et al. 2007). Thereafter, it grows intercellularly and intracellularly in the cortex towards the central cylinder and then colonizes the xylem vessels. Individual xylem vessels are filled with mycelium and conidia whereas neighboring vessels remain completely unaffected. As the diseased plant senesces, the fungus produces microsclerotia, which are released into the soil with the decomposition of plant material and can again infect healthy plants.

$V$. longisporum is confined for most part of its life in the host plant in the vascular system of rapeseed (Eynck et al. 2007). The xylem is responsible for the transport of water and soluble mineral nutrients from the roots throughout the plant. Xylem sap can also contain a number of organic acids, but it is not rich in nutrients (Lopez-Millan et al. 2000). The amino acid composition of the B. napus xylem is unknown. Glutamic acid, aspartic acid, and serine are the most abundant amino acids in leaf mesophyll cells of $B$. napus, where the concentration of the aromatic amino acids ranges from $1.2 \%$ to $2.1 \%$ of the total amino acids under low nitrogen supply condition (Tilsner et al. 2005).

Fungi are prototroph for amino acids and possess in addition elaborate amino acid uptake systems (Braus et al. 2004). The shikimate pathway is the general aromatic amino acid biosynthetic pathway present in fungi, bacteria, algae, and higher plants but is absent in mammals. The pathway converts D-erythrose 4-phosphate and phosphoenolpyruvate to chorismate and subsequently branches to produce tryptophan, phenylalanine, or tyrosine. In addition, the pathway is required for aromatic compounds like $p$-aminobenzoate, amino-hydroxybenzoate, vitamin $\mathrm{K}$, or ubiquinone (Bentley and Meganathan 1982; Jones et al. 1991; Hsu et al. 2000; Knaggs 2003; Draht et al. 2008) or aromatic secondary metabolites including terrequinone A in Aspergilli (Bok et al. 2006). Chorismate synthase (CS) catalyzes the conversion of 5-enolpyruvylshikimate-3-phosphate to chorismate, which is the seventh step of the pathway and is located prior to the branch point (Braus 1991).

A saprotrophic fungus has to adapt according to the surrounding environmental conditions. If nutrients like amino acids are scarce, amino acid biosynthesis has to be activated. However, if amino acids are present in the surrounding environment, they should be procured by amino acid uptake systems and their production should be reduced. Many fungi possess the cross-pathway control system to overcome an imbalanced amino acid diet, which is problematic due to several feedback or cross-feedback controlled multi-amino-acid pathways. The corresponding transcriptional activator is Gcn4 in Saccharomyces cerevisiae (Hinnebusch 1984) or CpcA in Aspergilli (Wanke et al. 1997; Eckert et al. 1999; Hoffmann et al. 2001; Krappmann et al. 2004). Gcn 4 protein is present in low levels when amino acids are abundant in the cell but becomes strongly induced under amino acid starvation condition (Albrecht et al. 1998). In the aromatic amino acid pathway of $S$. cerevisiae, four of the five TRP genes (Miozzari et al. 1978), the isogenes $A R O 3$ and ARO4 (Teshiba et al. 1986; Paravicini et al. 1989; Künzler et al. 1992), and the ARO2 gene are derepressed under the general control system. The genes TRP1 and TYR1 are not derepressible by this system (Braus 1991; Mannhaupt et al. 1989). The ARO7 gene, which encodes chorismate mutase (Helmstaedt et al. 2001) producing the precursor to phenylalanine and tyrosine, is not transcriptionally controlled by Gen 4 (Krappmann et al. 2000).

Here, we have identified and characterized Vlaro2, which encodes the $V$. longisporum CS required for the production of the three aromatic amino acids. We provide the first RNA-mediated silencing of the two isogenes of $V$. longisporum. The resulting bradytrophic mutant induces during saprotrophic growth and in planta constitutively the transcription of VlcpcA encoding the cross-pathway control transcription factor. In wild-type cells, VlcpcA transcription is low during saprotrophic growth under nonstarvation condition but is induced in planta. This suggests a low and imbalanced amino acid supply present in the plant xylem.

\section{Methods}

Strains, media, and growth conditions The $S$. cerevisiae strains BY4741 (wild type) and Y04515 (BY4741; Mata; his $3 \Delta 1$; leu $\Delta 0$; met15 $\Delta 0$; ura3 $\Delta 0$; YGL148w::kanMX4) were obtained from the Euroscarf (Frankfurt, Germany) collection. Strains were grown on yeast extract-peptone dextrose (YPD) medium or on synthetic complete (SC) medium at $30^{\circ} \mathrm{C}$. SC medium contained $2 \%$ glucose or $2 \%$ galactose, supplemented with the appropriate amino acids.

For maintenance and construction of plasmids, Escherichia coli SURE (Stratagene, CA, USA) cells and XL 10Gold ultracompetent cells (Stratagene, CA, USA) were used. They were grown at $37^{\circ} \mathrm{C}$ in Luria-Bertani (LB) broth or on LB plates, supplemented with ampicillin $\left(100 \mu \mathrm{g} \mathrm{ml}^{-1}\right)$ or kanamycin $\left(100 \mu \mathrm{g} \mathrm{ml}^{-1}\right)$, as required.

A. tumefaciens AGL-1 strain (Lazo et al. 1991) was used for plasmid maintenance and transformation of $V$. longisporum. It was grown in LB medium supplemented with 
carbenicillin $\left(50 \mu \mathrm{g} \mathrm{ml}^{-1}\right)$ and rifampicin $\left(25 \mu \mathrm{g} \mathrm{ml}^{-1}\right)$ at $28^{\circ} \mathrm{C}$.

The $V$. longisporum strain 43 and $V$. dahliae strain 73 (Zeise and von Tiedemann 2002) were used in this study. Czapek Dox Agar (CDA) was inoculated with fungal spores and incubated at $25^{\circ} \mathrm{C}$ for 4 to 10 days in dark.

Construction of the $V$. longisporum cDNA library Fungal mycelia growing in different nutrient media were collected with sterile Miracloth filter (Calbiochem, Darmstadt, Germany) and washed with sterile distilled water. They were ground separately in liquid nitrogen to fine powder using a mortar and a pestle. Total RNAs were isolated from the powdered fungal mycelia using the TRIzol reagent (Invitrogen $\mathrm{GmbH}$, Karlsruhe, Germany) according to the manufacturer's instructions. One milligram of total mixed RNA contained $10 \%$ RNA from the fungus growing in liquid minimal medium (MM) for 4 days, $25 \%$ RNA from the fungus growing in liquid MM for 10 days, $25 \%$ RNA from the fungus growing in liquid simulated xylem medium (SXM) for 4 days, 25\% from the fungus growing in liquid SXM for 10 days, and 15\% RNA from the fungus growing on potato dextrose agar for 10 days at $25^{\circ} \mathrm{C}$. The cDNA library of $V$. longisporum was generated in the yeast expression vector pYES-DEST52 by Invitrogen $\mathrm{GmbH}$ (Karlsruhe, Germany), and the DNA sequence of a sample of 5,000 expressed sequence tags was determined.

Yeast complementation assay V. longisporum cDNA library in the yeast expression vector, pYES-DEST52, was transformed in the yeast deletion mutant of CS, Y04515 ( $\triangle A R O 2$; Burke et al. 2000). Transformed cells were plated onto SC minus uracil medium supplemented with $2 \%$ glucose at $30^{\circ} \mathrm{C}$. The uracil prototrophs were subsequently replica-plated on SC plates supplemented with $2 \%$ galactose, lacking the three aromatic amino acids, at $30^{\circ} \mathrm{C}$.

Generation of the plasmid for silencing Vlaro2 in $V$. longisporum Recombinant DNA technology protocols were followed according to Sambrook et al. (1989). Polymerase chain reaction (PCR) was performed with $P f u$ proofreading polymerase (Stratagene, CA, USA), Hot start Taq DNA polymerase (Qiagen, Hilden, Germany), or Expand high-fidelity PCR system (Roche, Mannheim, Germany). Primers are listed in Table S1. Calcium-treated chemically competent cells of $E$. coli were transformed according to Hanahan et al. (1991). The pSilent-1 vector (Nakayashiki et al. 2005) was used for constructing the silencing cassette. A fragment of 418 bp was amplified from the coding region of Vlaro2 of $V$. longisporum by PCR using primers CSS-Sna-F and CSS-Hind-R to produce the sense strand. Sense product was purified and then digested with SnaBI and HindIII. It was then ligated into
SnaBI-HindIII-digested pSilent-1 plasmid. The antisense region of Vlaro2 was amplified using CSAS-ApaI-F and CSAS-PaeI-R. Antisense product was purified and then digested with $A p a \mathrm{I}$ and $S p h$ I. It was then ligated with ApaISphI-digested pSilent-1 plasmid already containing the sense Vlaro2. The whole silencing cassette consisting of $\operatorname{TrpC}$ promoter, sense Vlaro2 strand, spacer, antisense Vlaro2 strand, and $\operatorname{Trp} C$ terminator was isolated by

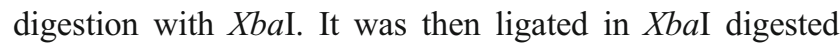
binary vector, pPK2 (Covert et al. 2001) to generate pME3571 vector for silencing both the isogenes Vlaro2-1 and Vlaro2-2. The pPK2 vector contains the hygromycin B phosphotransferase gene $(h p h)$ as selection marker.

Agrobacterium tumefaciens-mediated transformation $V$. longisporum was transformed by A. tumefaciens-mediated transformation as described by Mullins et al. (2001) with slight modifications. The pME3571 vector was transformed in A. tumefaciens AGL-1 strain by electroporation $(2,500 \mathrm{~V}$, $5 \mathrm{~ms}$ ) and plated on LB medium containing kanamycin $\left(100 \mu \mathrm{g} \mathrm{ml}^{-1}\right)$. The transformed strain was inoculated in LB medium supplemented with $50 \mu \mathrm{g} \mathrm{ml}^{-1}$ kanamycin and $100 \mu \mathrm{g} \mathrm{ml}^{-1}$ carbenicillin. Filter paper, $90 \mathrm{~mm}$ (Sartorius, Göttingen, Germany), was used for cocultivation of the $A$. tumefaciens culture and $V$. longisporum spore suspension. The transformants were obtained on selection medium containing $100 \mu \mathrm{g} \mathrm{ml}^{-1}$ hygromycin B. The mitotic stability of transformation was examined by culturing transformants on CDA for five generations successively and then transferring to selection medium with hygromycin B.

Southern hybridization analysis Genomic DNA of $V$. longisporum was isolated from mycelium grown in liquid culture (Kolar et al. 1988) and used for Southern hybridization (Southern 1975). Gel-purified DNA fragments (QIAquick Gel Extraction Kit from Qiagen, Hilden, Germany) consisting of a 400-bp fragment from Vlaro2 (Table S1) or a $1-\mathrm{kb}$ fragment from $h p h$ gene in pPK2 (Covert et al. 2001) were used as probes. Amersham CDPStar Detection reagent (GE Healthcare, Munich, Germany) was used for chemiluminescent signal detection.

RT-PCR analysis Total RNA was isolated from fungal mycelium using the TRIzol reagent from Invitrogen $\mathrm{GmbH}$, Karlsruhe, Germany according to the manufacturer's instructions. Total cDNA was generated using RevertAid First-Strand cDNA synthesis kit (Fermentas, St. Leon-Rot, Germany). PCR was performed using the Hot start Taq DNA polymerase (Qiagen, Hilden, Germany) with $1 \mu \mathrm{l}$ of reverse transcription (RT) reaction as template and $0.5 \mu \mathrm{M}$ of each primer. The VlcpcA gene was identified in the sequenced sample of the cDNA library of $V$. longisporum by multiple alignments with its fungal counterparts (data 
not shown). To detect VlcpcA mRNA, the primers SS85 and SS86 were used; for Vlaro2 mRNA, the primers SS46 and SS47 were applied, and the transcript for actin was recognized by the usage of the primers SS15 and SS33.

Western hybridization analysis Yeast Protein Extraction Reagent (Y-PER-S reagent, Pierce, Thermo Fisher Scientific, Schwerte, Germany) was used for protein extraction and protease inhibitor (Complete, protease inhibitor cocktail, Roche, Mannheim, Germany) was added during extraction. Protein concentrations were determined using the $\mathrm{BCA}^{\mathrm{TM}}$ protein assay kit (Pierce, Thermo Fisher Scientific, Schwerte, Germany). Protein extracts were separated by sodium dodecyl sulfate (SDS)-polyacrylamide electrophoresis (Laemmli 1970) for Western hybridization (Laxalt et al. 2002). CS antibody raised against $N$. crassa (Ehammer et al. 2007) and monoclonal mouse anti- $\alpha$-tubulin antibody (Sigma-Aldrich Chemie, Steinheim am Albuch, Germany) were used as primary antibodies. As secondary antibodies, peroxidase-coupled goat antirabbit immunoglobulin G (IgG)-horse radish peroxidase (Santa Cruz Biotechnology, Heidelberg, Germany) or goat antimouse IgG antibodies (Invitrogen GmbH, Karlsruhe, Germany) were employed. Cross-reactions were visualized using the electrochemiluminescence technology (Amersham Pharmacia Biotech, GE Healthcare, Munich, Germany).

Phenotypic analysis of Vlaro2-silenced mutants Five thousand spores of Vlaro2-silenced mutants (Vlaro2sm) and wild type were inoculated on CDA and CDA supplemented with the three aromatic amino acids tryptophan, phenylalanine, and tyrosine or $5 \mathrm{mM} \mathrm{5-methyl-DL-tryptophan} \mathrm{(5-}$ MT) at $25^{\circ} \mathrm{C}$. The experiment was performed in triplicate. The plates were observed every day until 4 days postinoculation (dpi) by light microscopy. For radial growth rate determination, the procedure described by Panepinto et al. (2003) was applied.

Xylem sap production and amino acid measurement Rapidcycle rape (genotype: ACaacc; Williams and Hill 1986) was used for xylem sap production. B. napus plants were harvested when they were 42 days old. Xylem sap was collected as described previously (Scholander et al. 1965; Kehr et al. 2005). The yield was $50-150 \mu l$ per plant. Xylem sap was filter-sterilized and stored at $-20^{\circ} \mathrm{C}$ until further use. The amino acids present in the xylem sap were analyzed by high-performance liquid chromatography (HPLC; Pharmacia/LKB, Freiburg, Germany) according to Riens et al. (1991).

Pathogenicity assay Week-old B. napus seedlings were inoculated with $1 \times 10^{6}$ spores per milliliter of Vlaro2-sm and wild type of $V$. longisporum and mock-inoculated with sterile tap water for $30 \mathrm{~min}$ by root-dipping inoculation. They were then transferred in pots with sterile sand/soil (1:1) mixture. The plants were incubated in a climate chamber with $14-\mathrm{h}$ light at $23^{\circ} \mathrm{C}$ and 10 -h dark at $20^{\circ} \mathrm{C}$. The height of inoculated plants was measured, and they were scored for disease symptoms according to Eynck et al. (2007).

A. thaliana plants were grown in sand/soil mixture (Vitakraft, Nr. 12262, Bremen, Germany) on a layer of seramis (Masterfoods, Viersen, Germany) in a growth chamber $\left(22^{\circ} \mathrm{C}\right.$, and $\left.\sim 140 \mu \mathrm{mol}^{-1} \mathrm{~m}^{2} \mathrm{~s}^{-1} \mathrm{PAR}\right)$ under short-day conditions (8-h-light/16-h-dark photoperiod). Three-week-old plants were inoculated by incubation for $45 \mathrm{~min}$ in a conidial suspension $\left(10^{6}\right.$ conidia per milliliter $)$ or mock-inoculated by dipping in sterile tap water. Plants were transplanted into potting mix (steam-sterilized soil) and kept under a transparent cover for 2 days to ensure high humidity. The leaf area of the inoculated plants was measured at 7, 14, 21, and $28 \mathrm{dpi}$. The fresh weight of the inoculated plants was measured at $28 \mathrm{dpi}$.

Quantification of gene expression and V. longisporum DNA in planta by real-time PCR Hypocotyls and stems $(5-6 \mathrm{~cm}$ from top of plant) were separated from the infected rapeseed plants harvested at 14,21, 28, and $35 \mathrm{dpi}$. Eighteen plants were harvested from each treatment. Infected $A$. thaliana plants were harvested at $28 \mathrm{dpi}$. DNA was extracted using the DNeasy Plant Mini Kit (Qiagen, Hilden, Germany), and RNA was extracted using the RNeasy Plant Mini Kit (Qiagen, Hilden, Germany). For induction with 5-MT, fungal mycelium from 4-day-old liquid culture in Czapek Dox (CD) medium was transferred in $\mathrm{CD}$ medium supplemented with $5 \mathrm{mM} 5$-MT and incubated for 8-h. Total cDNA was generated from the fungal mycelium as described before (RT-PCR analysis). The fungal DNA was quantified in the $B$. napus tissue with real-time PCR according to Eynck et al. (2007). Primers OLG 70 and OLG 71 amplify a fragment specific for $V$. longisporum and V. dahliae (Eynck et al. 2007). Vlaro2 was amplified using primers SS93 and SS94, VlcpcA using primers SS85 and SS86, and the gene for B-tubulin using primers SS57 and SS58 (Table S1).

Real-time PCR was carried out by using Fast Start DNA Master SYBR Green I kit (Roche, Mannheim, Germany) with $0.3 \mu \mathrm{M}$ of each primer and $2 \mu \mathrm{l}$ of template in a final reaction volume of $20 \mu \mathrm{l}$. Reactions were set up with three replicates per sample. Controls without templates were included for each primer set. For amplification and melting curve analysis, the Light Cycler 2.0 System (Roche, Mannheim, Germany) was used, initiated by 10 -min incubation at $95^{\circ} \mathrm{C}$, followed by 45 cycles of $10 \mathrm{~s}$ at $95^{\circ} \mathrm{C}, 10 \mathrm{~s}$ at $58^{\circ} \mathrm{C}$, and $25 \mathrm{~s}$ at $72^{\circ} \mathrm{C}$. The amount of DNA of $V$. longisporum was estimated by integration of a 
calibration curve using increasing amounts of genomic $V$. longisporum DNA from 1 to $625 \mathrm{pg}$, in the analysis. The real-time RT-PCR data were analyzed using the $2^{-\Delta \Delta \mathrm{Ct}}$ relative quantification method (Livak and Schmittgen 2001), taking the gene for ß-tubulin as reference for normalization.

V. longisporum DNA in A. thaliana was quantified by the iCycler System (Bio-Rad, Munich, Germany). The amplification mix consisted of $\mathrm{NH}_{4}$ reaction buffer (Bioline, Luckenwalde, Germany); $3 \mathrm{mM} \mathrm{MgCl} 2 ; 200 \mu \mathrm{M}$ of each dATP, dTTP, dCTP, and dGTP; $0.3 \mu \mathrm{M}$ of primer OLG70 and OLG71; $0.25 \mu \mathrm{M}$ BIOTaq DNA polymerase (Bioline, Luckenwalde, Germany); 10 nM Fluorescein (BioRad, Munich, Germany) 100,000 times diluted SYBR Green I solution (Cambrex, Bio Science Rockland, USA); 20-30 ng of template DNA; and double-distilled water filled to a total volume of $25 \mu \mathrm{l}$. PCR program comprised a 2-min denaturation step at $94^{\circ} \mathrm{C}$ followed by 36 cycles of $20 \mathrm{~s}$ at $94^{\circ} \mathrm{C}, 30 \mathrm{~s}$ at $59^{\circ} \mathrm{C}$, and $40 \mathrm{~s}$ at $72^{\circ} \mathrm{C}$. The amount of $V$. longisporum DNA was estimated from a calibration curve constructed with purified fungal DNA diluted with plant DNA. To normalize for different DNA preparations, the Arabidopsis Actin8 gene (At1g49240) was amplified with the primers act8fow and act8rew (Table S1). The amount of Actin8 DNA in the samples was calculated with a reference plasmid encoding Actin8 sequences. Copy number of the product was calculated from the threshold cycles of duplicate realtime PCR assays using the standard curve.

\section{Results}

Low concentrations of various amino acids are present in the xylem sap of B. napus

$V$. longisporum colonizes the rapeseed xylem, resulting in impairment of plant growth. The xylem primarily carries water and minerals from the root to the aerial parts of the plant. Additionally, the xylem sap also contains some organic acids and amino acids (Schurr and Schulze 1995; Zornoza et al. 1996; Satoh et al. 1998). To address the importance of amino acids as nutrient supply for fungal life, we investigated the amino acid composition in the xylem sap of $B$. napus. For this purpose, xylem sap was extracted from 42-day-old $B$. napus plants. At this time, the $B$. napus plants are mature and flowering, and if infected, they are heavily infected with $V$. longisporum. At this late stage of infection, the fungus spreads from the hypocotyl to the upper parts of the plant. The concentrations of the amino acids present in the xylem sap were determined by HPLC and are listed in Table 1. The amino acids cysteine and proline were not detectable with this HPLC system.
Table 1 Amino acid concentrations in the xylem sap of 42-day-old $B$. napus

\begin{tabular}{lr}
\hline Amino acid & Concentration $(\mu \mathrm{M})$ \\
\hline Asp & 52.85 \\
Glu & 53.66 \\
Asn & 9.72 \\
Ser & 37.34 \\
His & 4.12 \\
Gln & 177.35 \\
Thr & 22.82 \\
Gly & 17.76 \\
Arg & 2.76 \\
Ala & 36.32 \\
GABA & a \\
Tyr & 50.58 \\
Val & 7.94 \\
Met & 25.75 \\
Trp & 2.01 \\
Ile & 2.01 \\
Phe & 15.34 \\
Leu & 6.77 \\
Lys & 10.09 \\
Total & 8.83 \\
\hline & 544.02 \\
\hline
\end{tabular}

All values are an average of two measurements

${ }^{\mathrm{a}} \gamma$-Aminobutyric acid

${ }^{\mathrm{b}}$ Aromatic amino acids

The concentration of the amino acids ranged from 2 to $177 \mu \mathrm{M}$. The major amino acids are glutamine, glutamic acid, aspartic acid, and $\gamma$-amino butyric acid. $\gamma$-Amino butyric acid is produced by decarboxylation of glutamate (Satyanarayan and Nair 1990). Histidine, arginine, methionine, lysine, and aromatic amino acids were below $10 \mu \mathrm{M}$. The concentration of all aromatic amino acids was low, as tyrosine was $8 \mu \mathrm{M}$, tryptophan $2 \mu \mathrm{M}$, and phenylalanine $7 \mu \mathrm{M}$, respectively. It is unknown whether aromatic amino acids in these low concentrations are sufficient to support $V$. longisporum colonization of the xylem or whether the fungus primarily depends on its own aromatic amino acid biosynthesis.

\section{V. longisporum Vlaro2 complements the $S$. cerevisiae} ARO2 deletion mutant of $\mathrm{CS}$

We addressed whether the detected low aromatic amino acid concentration in the rapeseed xylem is sufficient to support fungal growth. We focused on the isogenes for the $\mathrm{CS}$ as the last common enzyme, which is required for the synthesis of all the aromatic amino acids of $V$. longisporum as well as other aromatic compounds (Weiss and Edwards 1980; Haslam 1993). The genomic database of the fungus 
is not yet available, and therefore we isolated the genes by heterologous complementation. We constructed a $V$. longisporum cDNA library whose expression in yeast is driven by the GAL1 promoter to complement a yeast $\triangle A R O 2$ mutant strain. ARO2 encodes the yeast $\mathrm{CS}$, and yeast $\triangle A R O 2$ mutant strain cannot grow if the three aromatic amino acids are not added to the medium (Jones et al. 1991).

Several transformants derived from the cDNA library of $V$. longisporum in the $S$. cerevisiae $\triangle A R O 2$ mutant strain were obtained on SC medium lacking the three aromatic amino acids. For its function, CS has an absolute requirement for reduced FMN. CS from plants and eubacteria depends on external sources for the reduction of FMN. In contrast, CS of $S$. cerevisiae is bifunctional as, along with the catalysis of 5-enolpyruvylshikimate 3-phosphate to chorismate, it also possesses an additional NADPH:FMN oxidoreductase activity (Henstrand et al. 1996). This additional function is required for generating reduced FMN for the catalytic activity of the enzyme. The successful complementation of the yeast $\triangle A R O 2$ mutant strain suggests that $V$. longisporum also encodes a bifunctional CS.

Eight randomly picked complements were analyzed, and the inserts of the plasmids revealed identical cDNA sequences for all plasmids. Comparison of the deduced amino acid sequence of this cDNA with the GenBank National Center for Biotechnology and European Molecular Biology Laboratory database revealed a putative gene for CS. Therefore, the gene was named Vlaro2. Retransformation of the isolated plasmid confirmed the complementation resulting in similar growth results as the wild-type yeast strain (BY4751), whereas the untransformed $\triangle A R O 2$ cannot grow on SC medium lacking the three aromatic amino acids (Fig. 1a).

The sequence analysis revealed that the coding region of Vlaro 2 comprises an open reading frame of 1,227 bp (EMBL database accession number FM999811). The deduced protein Vlaro2 consists of 408 amino acids and has a predicted molecular mass of $43.57 \mathrm{kDa}$ (Fig. 1b). Vlaro2 is identical to the corresponding protein sequence of $V$. dahliae (Locus ID: VDAG_07695.1), but the analysis of the introns showed that the $V$. longisporum gene includes a shorter intron of 74-bp in comparison to the 81-bp intron of $V$. dahliae. In the analysis of the draft genome of $V$. dahliae, only one gene locus on chromosome 5 for CS could be found (http://www.broadinstitute. org/annotation/genome/verticillium_dahliae/GeneDetails. html? sp=S7000001884963178, 13 September 2009). There is also high sequence similarity of the deduced primary sequence to CSs from other filamentous fungi including Neurospora crassa (76\% identity) or S. cerevisiae (63\% identity; Fig. S1). Sequence similarity was lower with CS proteins from bacteria (Desulfuromonas acetoxidans $55 \%$ identity) or plants (Oryza sativa 52\%
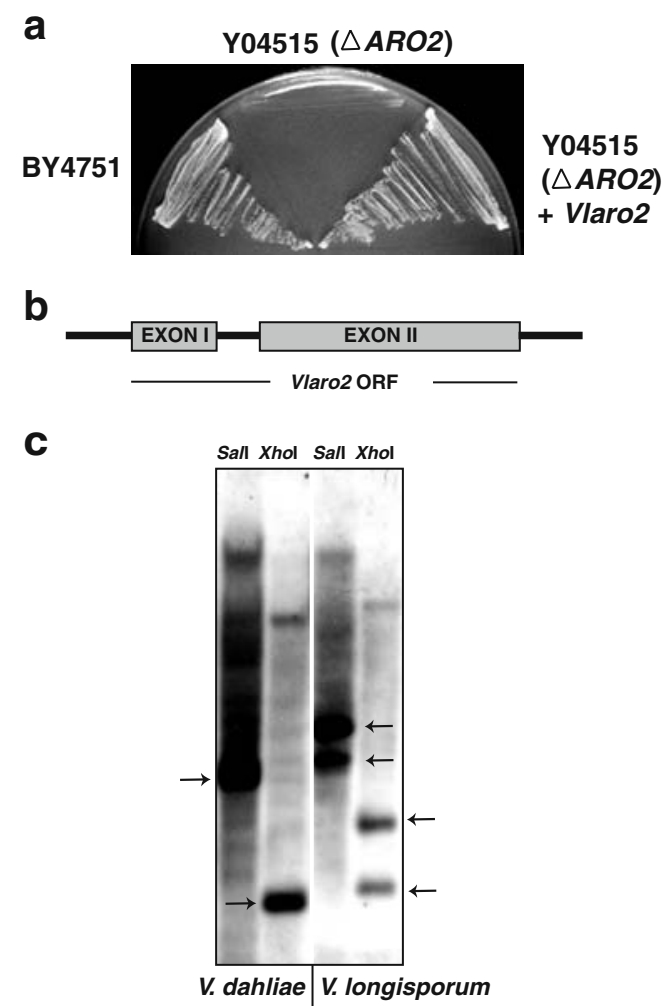

Fig. 1 Isolation of the gene for $\mathrm{CS}$ in $V$. longisporum, Vlaro2. a $\triangle A R O 2$ yeast complementation assay on $\mathrm{SC}$ medium lacking the three aromatic amino acids. BY4751, wild-type yeast strain; $Y 04515$

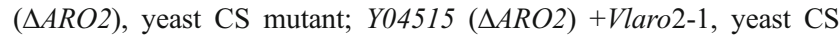
mutant complemented with gene for $\mathrm{CS}$ in $V$. longisporum. b Illustration of the Vlaro2-1 locus consisting of two exons and one intron. c Determination of the isogene Vlaro2-2 of Vlaro2-1 by Southern hybridization analysis of $V$. dahliae and $V$. longisporum. The genomic DNA was digested with SalI and XhoI. A 416-bp sequence of Vlaro2-1 was used as a probe. Arrows indicate the signal generation by probe binding

identity). L1, L2, and L4, the regions that contribute to the substrate binding site in CS of S. cerevisiae (QuevillonCheruel et al. 2004), could also be identified in Vlaro2 and are shown in Fig. S1. The NADPH binding region is yet unclear. Kitzing et al. (2001) observed that NADPH binds in or near the substrate (5-enolpyruvylshikimate 3-phosphate) binding site, suggesting that NADPH binding to bifunctional CSs is embedded in the general protein structure, and a special NADPH binding domain is not required to generate the intrinsic oxidoreductase activity.

$V$. longisporum has been described as "near-diploid" organism because it possesses 1.78 times the DNA content of $V$. dahliae, one of its parent species (Karapapa et al. 1997). Since we found only one type of complementing cDNAs for Vlaro2, we analyzed the copy number of the gene within the genome by Southern hybridization. $V$. longisporum and $V$. dahliae genomic DNA were compared and digested with SalI and XhoI (Fig. 1c). Restriction sites for both enzymes are not present within the Vlaro2 gene. A 
unique and fully sequenced 416-bp Vlaro2 fragment from $V$. longisporum was used as probe (Table $\mathrm{S} 1$ ). Two signals were generated for $V$. longisporum as compared to $V$. dahliae for the genomic DNA. These data suggest the presence of two similar isogenes (Vlaro2-1 and Vlaro2-2) for CS within the genome of $V$. longisporum. It is currently unknown whether and to what degree both genes are expressed.

Vlaro2 isogenes were silenced up to $80-90 \%$ by RNA-mediated gene silencing

To generate mutant strains impaired in aromatic amino acid biosynthesis, we had to take into account that both isogenes of Vlaro2 might be expressed. RNA-mediated gene silencing has been successfully implemented in several fungi for targeted gene silencing instead of a conventional knockout (Nakayashiki et al. 2005). The binary vector pME3571 (Fig. S2) used for the silencing strategy in $V$. longisporum was based on pSilent-1 vector (Nakayashiki et al. 2005). It harbors the hairpin construct for silencing of Vlaro2 comprising of inverted repeats of Vlaro2 fragment separated by a spacer and the hygromycin gene as selection marker. Transformation in $V$. longisporum was mediated by A. tumefaciens. The transformants were grown on medium lacking hygromycin $\mathrm{B}$ for five generations and then grown on medium supplemented with hygromycin $B$, where only mitotically stable transformants could grow. Thirty independent hygromycin-B-resistant transformants were selected at random for further analysis. The integration of the T-DNA in the genome of the $V$. longisporum was confirmed by Southern hybridization analysis with a probe for the hygromycin resistance gene (Fig. 2a).

The extent of Vlaro 2 silencing was monitored by RT-PCR as the silencing of gene expression is the result of posttranscriptional degradation of targeted mRNA. Total RNA was extracted from the Vlaro2sm and wild type. RTPCR results showed the significant knockdown of Vlaro2 transcript (Fig. 2b). The degree of silencing of CS genes was estimated by RT-PCR by the ratio of the amplification of Vlaro2 between the respective transformants and the unsilenced wild type. High-frequency silencing was observed for $71 \%$ of the transformants exhibiting reduced gene expression. The extent of silencing varied in the different transformants between high and moderate levels.

We verified these results by monitoring the protein levels of Vlaro2 for all Vlaro2sm in comparison to wild type (Fig. 2c). Western hybridization using a CS-specific antibody and the tubulin levels as control showed the significant knockdown of Vlaro2 up to $94 \%$ in the Vlaro2sm as compared to the wild type. The knockdown of Vlaro2 at the protein level corresponded to the RT-PCR analysis of the Vlaro2sm and established gene silencing in
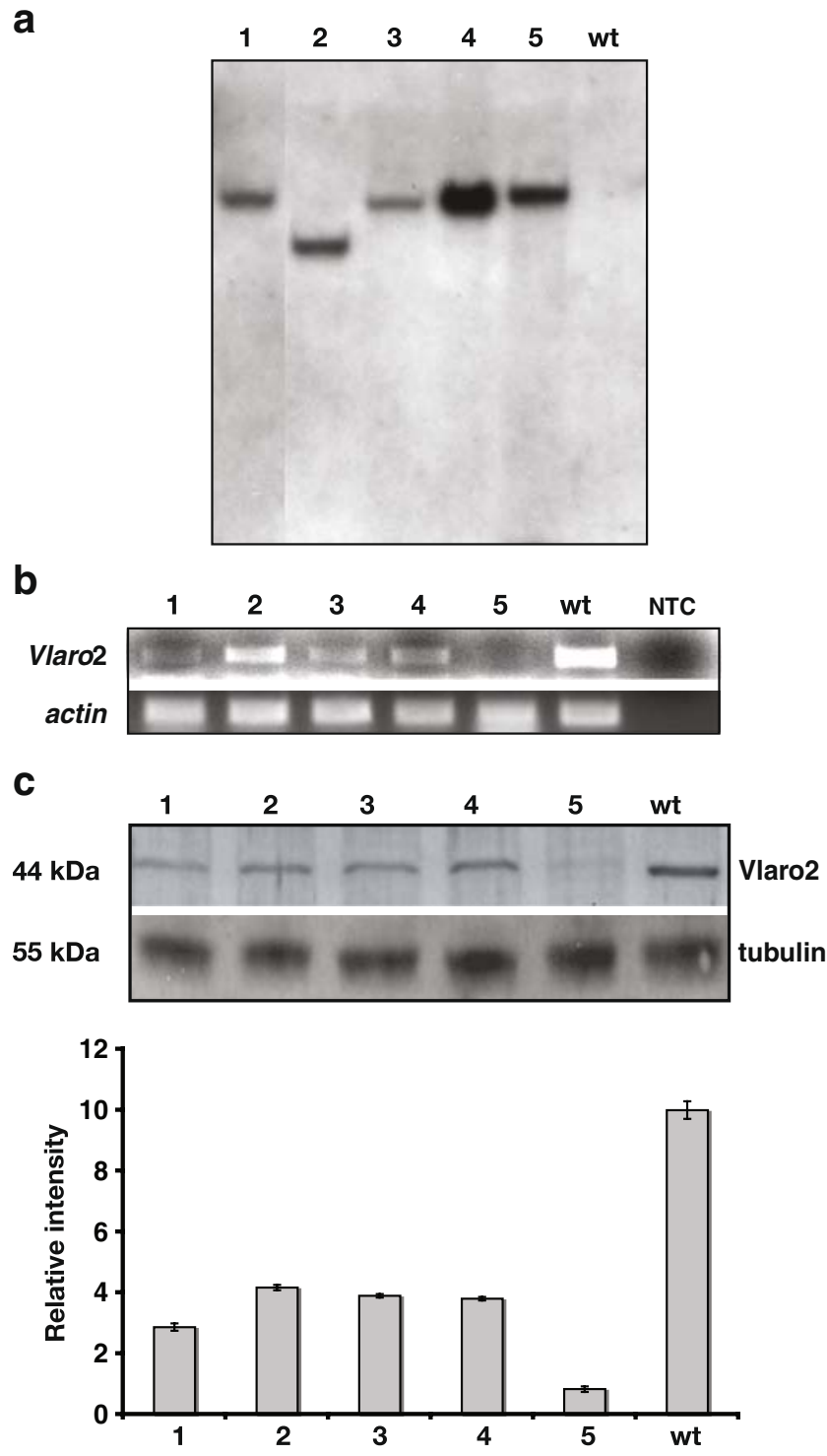

Fig. 2 Characterization of the Vlaro2 silenced mutants. a Southern hybridization analysis of Vlaro2 silenced mutants to detect integration of T-DNA after A. tumefaciens-mediated transformation. Five Vlaro2 silenced mutants (1-5) and wild-type ( $w t)$ gDNA was digested with HindIII and the hygromycin resistance gene was used as a probe. All mutants showed single integration of the gene. b RT-PCR analysis of Vlaro 2 mRNA expression in the Vlaro 2 silenced mutants. For RNA integrity, the actin gene was used as a control. 1-5, Vlaro2 silenced mutants; $w t$, wild type; NTC, no template control. c Western hybridization analysis of Vlaro2 expression in the Vlaro 2 silenced mutants compared to the wild type. Proteins were extracted from the Vlaro2 silenced mutants and wild type, ran on SDS-polyacrylamide gel, blotted and probed with $N$. crassa CS antibody. The same blot was stripped and probed again with Rat $\operatorname{IgG}$ tubulin antibody as a control. 1-5, Vlaro2 silenced mutants; wt, wild type. In the graph, CS expression was quantified and normalized against the tubulin level for the different samples using Kodak Molecular Imaging 4.05 software. Data represent average \pm standard deviations of three experimental replicates 
V. longisporum. Vlaro2sm 1 with $80 \%$ knockdown of Vlaro2 was chosen for further analysis.

Silencing of Vlaro2 results in a bradytrophic $V$. longisporum mutant

We analyzed the saprotrophic lifestyle of the Vlaro2sm and investigated whether Vlaro2 silencing inhibits the growth of $V$. longisporum in the absence of amino acids, specifically

a

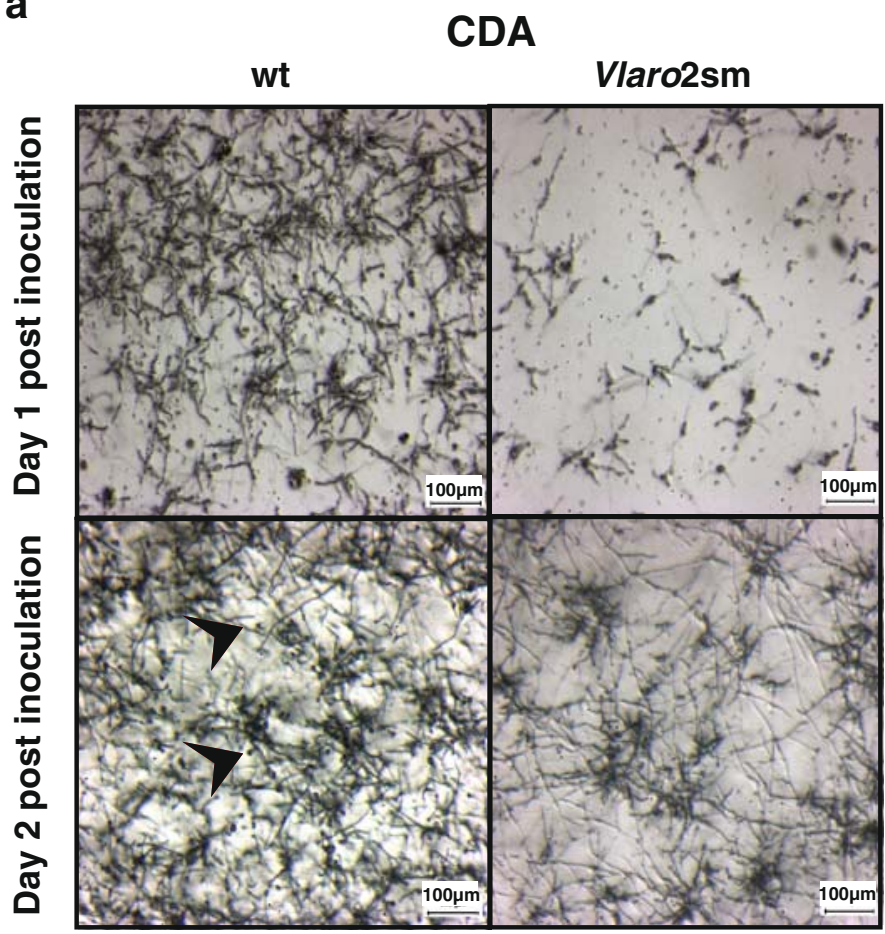

C

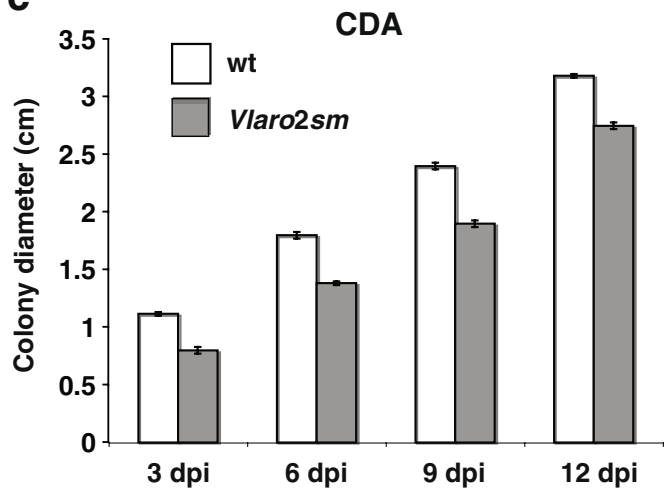

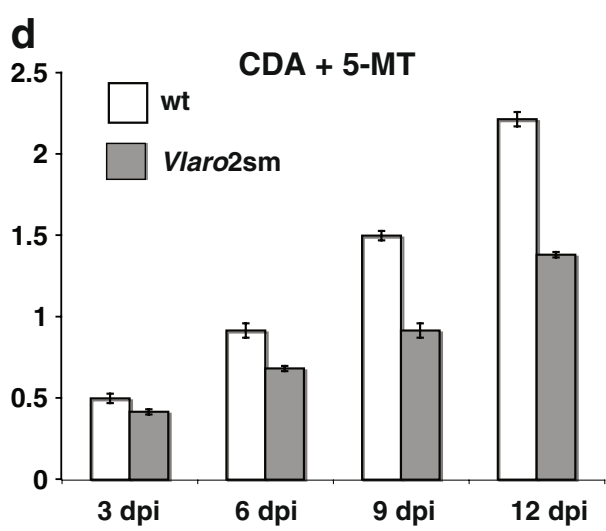

Fig. 3 Phenotypic analysis of the Vlaro2 silenced mutants. a Light microscopy images of $V$. longisporum wild type (wt) and Vlaro2 silenced mutant (Vlaro2sm) cultured on CDA as observed at 1 and 2 dpi. The colonies were examined microscopically for vegetative growth and spore formation. Black arrows indicate conidia. b Light microscopy images of $V$. longisporum wild type (wt) and Vlaro2sm cultured on CDA supplemented with $5 \mathrm{mM} 5$-MT as observed at 1 and 2 dpi. The colonies were examined microscopically for vegetative growth and spore formation. Black arrows indicate conidia. c The aromatic amino acids. One day after inoculation on CDA, notably, Vlaro2sm grew slowly. Only short hyphae were visible in contrast to the mycelial growth of wild type (Fig. 3a). After 2 days of inoculation on CDA, wild-type mycelial growth increased, and many conidia could be observed whereas the Vlaro2sm showed less mycelial growth and no conidia were observed. We further analyzed the effect of Vlaro2 silencing on the radial growth of $V$. longisporum. The radial growth of Vlaro $2 \mathrm{sm}$ recorded after

b

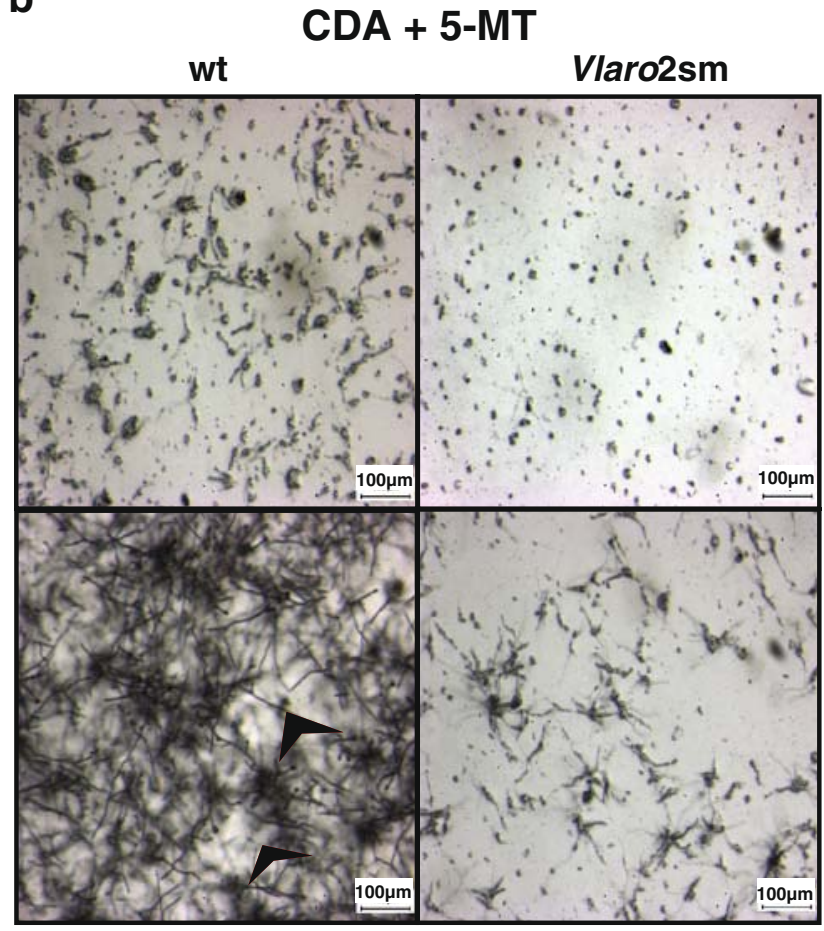

graph shows the growth rates of wild-type (wt) and Vlaro2sm on CDA determined by plate-based growth assays. Agar plates were inoculated with 5,000 spores, and colony diameter from three replicates was measured following 3, 6, 9, and 12 days of incubation at $25^{\circ} \mathrm{C}$. Data represent average \pm standard deviations of three experimental replicates. d The graph shows the growth rates of wild type (wt) and Vlaro2sm on CDA amended with 5-MT determined as described in 
3, 6, 9, or 12 days was similar to wild type (Fig. 3c). Therefore, the Vlaro2sm, showed only slower initial vegetative growth, but the radial growth was not affected compared to wild type.

Next, we analyzed the effect of the tryptophan analog, 5MT, on Vlaro2sm. Addition of 5-MT to CDA causes additional tryptophan starvation. 5-MT acts as false feedback inhibitor of anthranilate synthase, the first enzyme of the tryptophan branch of the pathway (Schuerch et al. 1974). One day after inoculation, the wild type formed short hyphae compared to Vlaro2sm in which only initial germination of conidia could be observed (Fig. 3b). After 2 days, wild type showed a mycelial net with few conidia, whereas Vlaro2sm formed short hyphae without conidia. Interestingly, the radial growth of Vlaro2sm was significantly lower than in the wild type when the colony diameter was determined until 12 days (Fig. 3d). It started decreasing gradually at 3 and 6 dpi and decreased up to $40 \%$ at 9 and 12 dpi. Hence, Vlaro2sm showed severe reduction in initial vegetative growth as well as the growth rate observed under saprotrophic conditions on CDA supplemented with 5-MT. As control, we analyzed whether tryptophan addition can counteract the 5-MT effect on Vlaro2sm growth. For this experiment, Vlaro2sm was inoculated on CDA medium supplemented with $5 \mathrm{mM} 5$-MT and $200 \mu \mathrm{M}$ tryptophan. The addition of tryptophan prevented the severe reduction in growth of the Vlaro2sm as observed in the presence of 5MT alone (data not shown).

We also studied the effect of the three aromatic amino acids on Vlaro $2 \mathrm{sm}$. The three aromatic amino acids were added to CDA, in concentration similar to the xylem sap of B. napus (Table 1), that is, $10 \mu \mathrm{M}$ phenylalanine, $10 \mu \mathrm{M}$ tyrosine, and $2 \mu \mathrm{M}$ tryptophan, respectively. Vlaro2sm again showed slower growth than the wild type. Higher concentration of 100 or $300 \mu \mathrm{M}\left(50 \mu \mathrm{g} \mathrm{ml}^{-1}\right)$ phenylalanine, 100 or $165 \mu \mathrm{M}\left(30 \mu \mathrm{g} \mathrm{ml}^{-1}\right)$ tyrosine, and 20 or $196 \mu \mathrm{M}\left(40 \mu \mathrm{g} \mathrm{ml}^{-1}\right)$ tryptophan did not stimulate growth of Vlaro2sm. This might be due to the fact that in fungi there are phenylalanine and tyrosine-feedback-inhibited isozymes for DAHP synthase, the initial enzyme of the pathway, but no tryptophan-dependent enzyme (Braus 1991). These data suggest that the concentration of the aromatic amino acids in the xylem sap is not high enough to allow growth of Vlaro2sm similar to wild type without support of cellular aromatic amino acid biosynthesis.

Vlaro2 silencing induces increased expression of the gene for the putative amino acid cross-pathway control activator, $V l c p c A$ during saprotrophic life

The knockdown of Vlaro2 resulted in reduced vegetative growth which became more retarded in presence of 5-MT as it produces less chorismate and is not able to cope with a
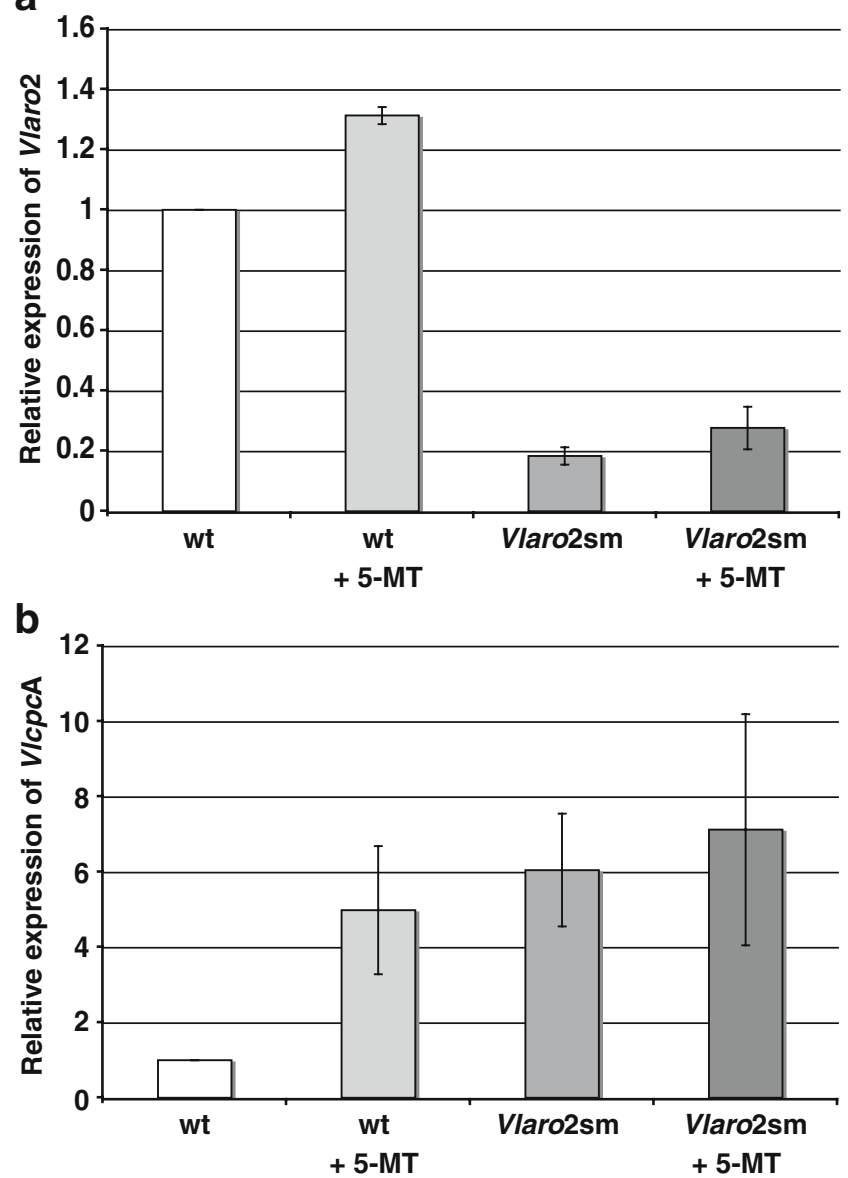

Fig. 4 Vlaro2 and VlcpcA expression. a Relative expression of Vlaro 2 measured by quantitative real-time PCR. Vlaro 2 cDNA was normalized to the $\beta$-tubulin cDNA. $w$ t, wild type, Vlaro $2 s m+5$-MT, $V$. longisporum strains grown in the presence of 5-MT. The error bars represent the standard deviations of three different measurements of the same cDNA. b VlcpcA expression measured relative to the $\mathrm{B}$ tubulin cDNA as described in a

tryptophan starvation. Quantitative real-time PCR was performed to determine the expression of Vlaro2 in wild type and Vlaro2sm under induction with 5-MT. Total RNA was extracted from the liquid cultures, and Vlaro2 expression was quantified by real-time PCR using $\beta$ tubulin gene for normalization. The expression of Vlaro2 in Vlaro2sm was drastically reduced by $82 \%$ compared to wild type (Fig. 4a). 5-MT only slightly affected Vlaro 2 expression in wild type or Vlaro2sm.

We addressed whether the Vlaro2sm counteracts amino acid stress by a cross-pathway control system as described for other fungi. We determined by quantitative real-time PCR whether silencing of Vlaro 2 induces the expression of the putative amino acid cross-pathway control transcriptional activator, VlcpcA. The samples used for expression study of VlcpcA and Vlaro2 were identical. VlcpcA expression was increased significantly by sixfold in the 
bradytrophic Vlaro2sm, suggesting that there is here as well amino acid starvation as a counteraction of a cross-pathway control (Fig. 4b). This is similar to the effect observed in $A$. nidulans where $c p c A$ mRNA levels were increased when cells were starved for amino acids (Hoffmann et al. 2001). The expression of $V l c p c A$ was increased by fivefold and sevenfold in wild type and Vlaro2sm cultures induced with 5-MT, respectively. Therefore, our data suggest that there exists a cross-pathway control for amino acid biosynthesis in $V$. longisporum.

Vlaro $2 \mathrm{sm}$ are able to infect $B$. napus xylem with reduced efficiency

Silencing of Vlaro2 resulted in an increase in VlcpcA expression that hints to a constitutively active crosspathway control. We analyzed whether such a $V$. longisporum mutant strain was still able to infect and colonize B. napus and the model plant, A. thaliana.

To assess the severity of disease, 1-week-old B. napus and 3-week-old $A$. thaliana seedlings were infected by root dip inoculation; the height of the plants was measured weekly postinoculation until the plants are highly infected. The plants began to show disease symptoms at $21 \mathrm{dpi}$ and were heavily infected at 35 dpi (Fig. 5a). The plants infected with Vlaro2sm were smaller than the mockinoculated plants, suggesting that the fungus had successfully infected the plant (Fig. 5c). Infection by Vlaro $2 \mathrm{sm}$ was less pronounced than by the wild type resulting in reduced stunting compared to that caused by wild type. At $35 \mathrm{dpi}$, the wild type and the Vlaro2sm-infected rapeseed plants were about $40 \%$ and $25 \%$ smaller than the mockinoculated plants, respectively (Fig. 5b). The infected rapeseed plants were also scored for disease symptoms by assigning disease scores from 1 to 9 corresponding to asymptomatic to dead plants (Eynck et al. 2007). The plants were observed weekly for disease symptoms until 35 dpi when the plants were highly infected. In the assessment of the symptoms, the yellowing and death of the leaves were considered. Therefore, the mock-infected plants also had disease scores more than 1 because of yellowing of leaves due to natural senescence. The infected plants did not show any disease symptoms until 14 dpi. The disease score of the Vlaro2sm-infected plants was slightly higher (4.5) than the mock-inoculated plants (4.0) but significantly lower than the plants infected with wild type (6.0; Fig. 5a).

In $A$. thaliana, the leaf area of the infected plants was measured weekly until 28 dpi. The difference in wild-typeinoculated and Vlaro2sm-infected plants became evident at $21 \mathrm{dpi}$ and became most pronounced at 28 dpi (Fig. 5d, e). At $28 \mathrm{dpi}$, when the plants were highly infected, the leaf area of the wild-type-inoculated plants was reduced by $50 \%$ than the mock-inoculated plants whereas the leaf area of the Vlaro2sm-infected plants was only reduced by $15 \%$ (Fig. 5d). The fresh weight of the A. thaliana plants was also measured at $28 \mathrm{dpi}$. The average weight of wild-typeinoculated plants was the least and reduced by $44 \%$ compared to the mock-inoculated plants. The fresh weight of Vlaro2sm-infected plants was reduced by $22 \%$ compared to the mock-inoculated plants. These data suggest that the bradytrophic mutant is able to colonize the plant and to induce disease but with significantly reduced efficiency in comparison to the wild type. It also suggests that $A$. thaliana is suitable for conducting pathogenicity assays with future mutants as it is easier to handle this wellestablished plant model system. Final conclusions on pathogenicity have always to be verified in the main host plant B. napus.

V. longisporum DNA in plant tissue infected with Vlaro2sm correlate with reduced virulence

Saprotrophic vegetative growth of Vlaro2sm was reduced without aromatic amino acids, and disease symptoms in the plant were also reduced. We analyzed whether there is also reduced growth of the mutant in the plant or whether the plant is able to inhibit fungal growth. Therefore, the total biomass of $V$. longisporum in B. napus infected with Vlaro $2 \mathrm{sm}$ versus wild type was analyzed by quantification of the $V$. longisporum DNA in the plant tissue by real-time PCR. The hypocotyls and top stems were harvested from the rapeseed plants infected with wild type or Vlaro2sm at various time points. Total DNA was extracted from the plant tissue, and the fungal DNA was quantified with realtime PCR. In the plant stem, at $21 \mathrm{dpi}$, there was negligible amount of $V$. longisporum DNA in the tissue samples of both wild type and Vlaro $2 \mathrm{sm}$. At 28 and $35 \mathrm{dpi}$, the amount of $V$. longisporum DNA was significantly lower $(13 \%$ and $3 \%$, respectively) in Vlaro2sm-infected plants in comparison to wild type (Fig. 6a). At $35 \mathrm{dpi}$, the V. longisporum DNA amount increased dramatically in the stem of wildtype-infected plants probably due to the outbreak of infection in the whole plant at this late stage of infection (Eynck et al. 2007). In the hypocotyls, V. longisporum DNA concentration was lower (5-34\%) in Vlaro2sminfected plants compared to the wild-type-infected plants throughout the infection study from early stage of infection at 14 dpi to late stage of infection at $35 \mathrm{dpi}$ (Fig. 6b).

Similarly, the DNA of $V$. longisporum in A. thaliana infected with Vlaro2sm versus wild type was analyzed by real-time PCR. At 28 dpi, $V$. longisporum DNA was present but represented in Vlaro $2 \mathrm{sm}$-infected plants only $5 \%$ of the fungal DNA in wild-type-infected plants (Fig. 6c). Therefore, the reduced amounts of $V$. longisporum DNA in Vlaro2sm-infected B. napus and A. thaliana plants corre- 
a

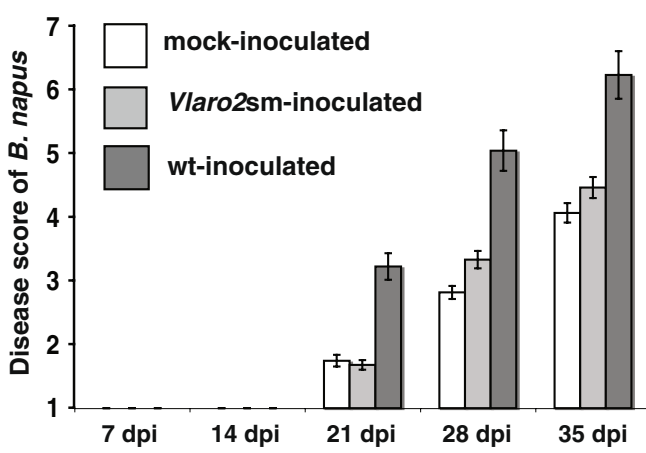

b
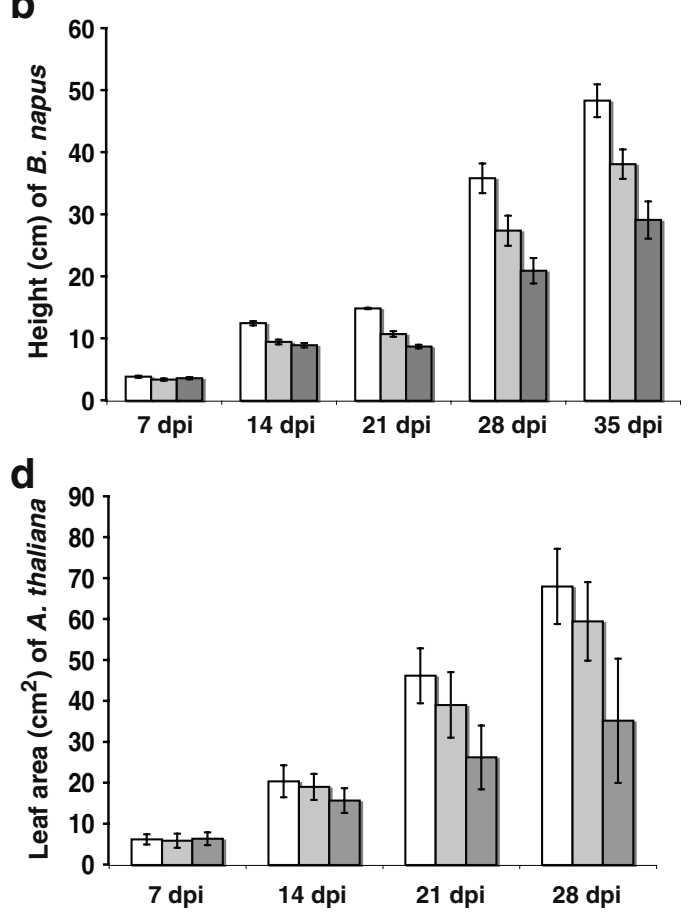

C

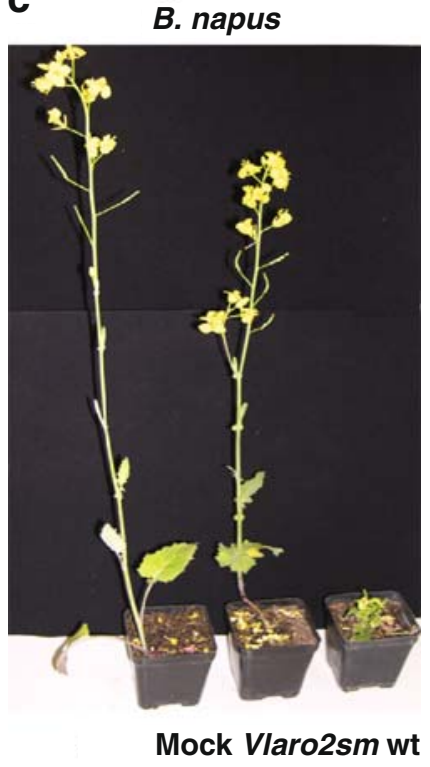

e

\section{A. thaliana}

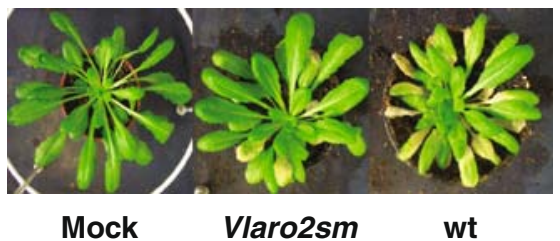

Fig. 5 Assessment of pathogenicity of the Vlaro2 silenced mutant. a Assessment of disease development by scoring for disease symptoms according to Eynck et al. (2007). Plants were scored for disease symptoms at $7,14,21,28$, and 35 dpi. Data represent average \pm standard deviations of 20 experimental replicates. $w t$, wild type; Vlaro2sm, Vlaro2 silenced mutant; mock, mock inoculation with water. b Assessment of stunting of rapeseed due to $V$. longisporum infection. The height of 20 replicates each of rapeseed plants infected with wild type (wt) and Vlaro2 silenced mutant (Vlaro2sm) was measured at 7, 14, 21, 28, and 35 dpi. For comparison, the height of rapeseed plants mock-inoculated (mock) with tap water was also

lated to the slower growth and the reduced virulence of the mutant.

The cross-pathway regulator, VlcpcA is induced during infection of $B$. napus and A. thaliana

We compared the expression of Vlaro2 in B. napus infected with $V$. longisporum wild-type strain and B. napus infected with Vlaro2sm to analyze whether the expression of Vlaro2 measured. The plants are heavily infected at 28 and 35 dpi. Data represent average \pm standard deviations of 20 experimental replicates. c Rapeseed infection assay. Representative B. napus plants shown at 35 dpi. d Assessment of disease development in A. thaliana by measuring the leaf area. The area of the leaves of $A$. thaliana plants infected with wild type (wt), Vlaro2 silenced mutant (Vlaro2sm) or mock-inoculated with water was measured at 7, 14, 21, and 28 dpi. Data represent average \pm standard deviations of 30 experimental replicates. e Arabidopsis infection assay. A. thaliana plants are shown at 28 dpi

is reduced in Vlaro2sm after infection of B. napus. The hypocotyls were harvested from the rapeseed plants infected with wild type or Vlaro $2 \mathrm{sm}$ at 35 days post inoculation. Total RNA was extracted from the hypocotyls and quantitative real-time PCR was performed for Vlaro2 expression in mutant and wild type. Vlaro2 was still expressed but significantly reduced to $14 \%$ in the hypocotyl from B. napus infected with Vlaro2sm as compared to the expression in the wild type (Fig. 7a). Similar Vlaro2 
a
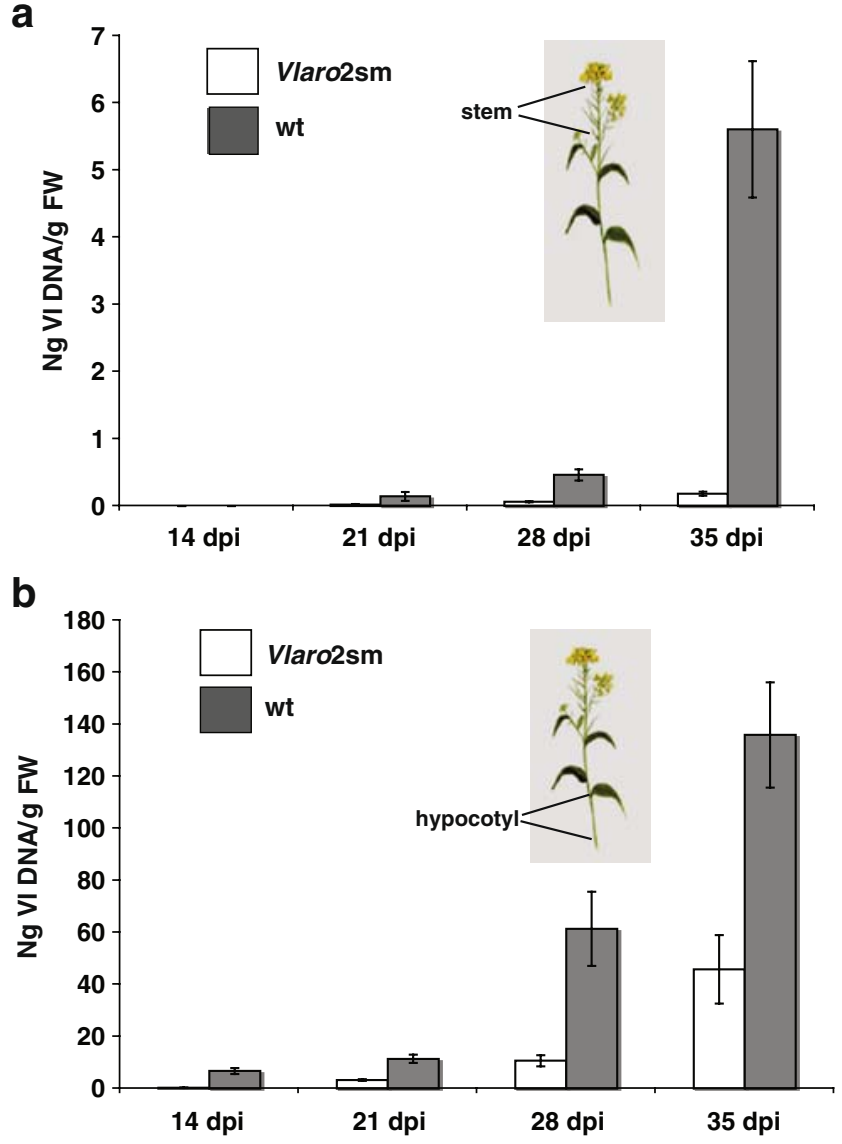

C

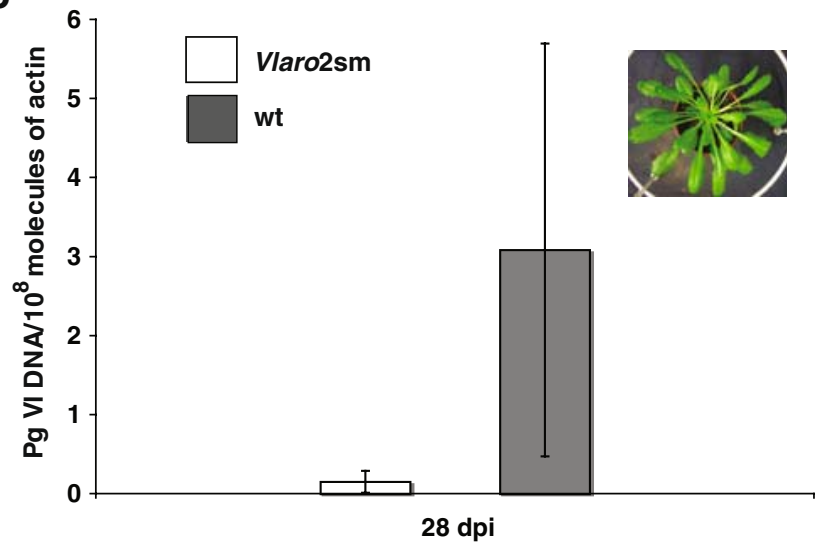

expression was also observed in Vlaro2sm infected $A$. thaliana and wild-type-infected A. thaliana (Fig. 7b). Therefore, Vlaro2 expression was similarly reduced in Vlaro2sm in infected plants and in liquid culture (Fig. 4a).

We also compared the expression of the CS encoding gene with the expression of the gene for the cross-pathway regulator $\mathrm{CpcA}$ as an indicator for amino acid starvation. The VlcpcA expression was increased 3.5-fold and 5.3-fold in the hypocotyl from $B$. napus infected with wild type and Vlaro2sm, respectively, compared to the expression in wildtype liquid culture (Fig. 7c). The VlcpcA expression in
Fig. 6 Infection assay and determination of the $V$. longisporum DNA concentration in the infected plant tissue. a $V$. longisporum DNA concentration in the plant stem. b $V$. longisporum DNA concentration in the hypocotyl. $V$. longisporum DNA was measured with real-time PCR in stem and hypocotyl of B. napus inoculated with Vlaro2 silenced mutant (Vlaro2sm) and wild type (wt) at 14, 21, 28, and 35 dpi. Data represent average \pm standard deviations of three experimental replicates. The mock-inoculated plants as a control did not show presence of any $V$. longisporum DNA. $N g V L D N A / g F W=$ nanogram $V$. longisporum DNA/gram fresh weight of plant tissue. (In the inset, a representative rapeseed plant depicting the stem $(5-6 \mathrm{~cm}$ from the top) and the hypocotyl harvested for the quantification of the $V$. longisporum DNA is shown). c $V$. longisporum DNA concentration in $A$. thaliana. DNA was measured with real-time PCR in A. thaliana inoculated with Vlaro2 silenced mutant (Vlaro2sm) and wild type (wt) at 28 dpi. Data represent average \pm standard deviations of three experimental replicates. The mock-inoculated plants as a control did not show presence of any $\mathrm{V}$. longisporum DNA. $\mathrm{Pg} V l \mathrm{DNA} / 10^{8}$ molecules of actin, picogram $V$. longisporum DNA $110^{8}$ molecules of actin of $A$. thaliana

wild-type-infected $A$. thaliana increased 2.6-fold and in Vlaro2sm infected $A$. thaliana 5.8-fold compared to the expression in wild-type liquid culture (Fig. 7d). The upregulation of $V l c p c A$ in plants infected with wild type suggests that this is due to $V$. longisporum encountering general amino acid starvation during biotrophic growth. We assume that the low levels of amino acids present in the xylem sap create an amino acid imbalance resulting in amino acid starvation and then "turn on" the cross-pathway control.

\section{Discussion}

The vascular pathogen $V$. longisporum inhabits the xylem vessels of the $B$. napus plant during colonization and infection of this oilseed crop. The xylem sap contains water, inorganic compounds, amino acids, and organic acids (Satoh et al. 1998; Kehr et al. 2005). In this study, we present the first construction of a $V$. longisporum mutant strain, which is bradytrophic for aromatic amino acids. This strain is suited to explore whether $V$. longisporum is exploiting the xylem sap for nutrition or is utilizing its inherent amino acid biosynthetic pathways during its biotrophic phase. We studied the $V$. longisporum CS which catalyzes the production of chorismate, the last common precursor of the aromatic amino acids in the shikimate pathway. RNA-mediated gene silencing was exploited to generate Vlaro2 knockdown strains in $V$. longisporum because it acts in a sequence-specific manner (Matityahu et al. 2008) as opposed to the knockout strategy that functions in a locus-specific manner. Silencing is suitable for heterokaryons or polyploid organism like $V$. longisporum (de Jong et al. 2006) and has been also successfully applied in other fungi (Tanguay et al. 2006; 
a

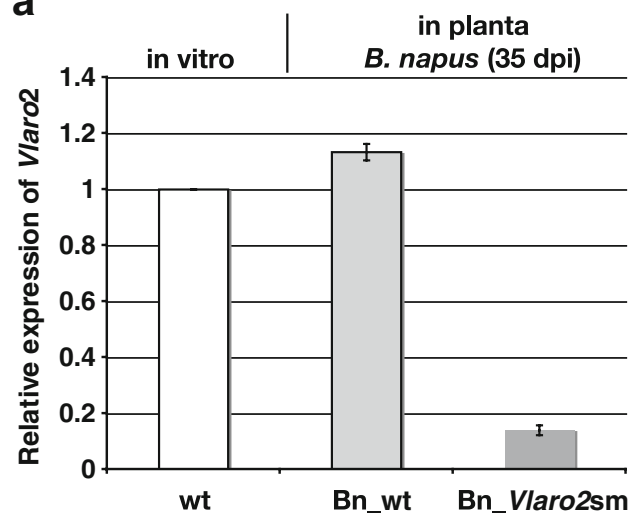

C

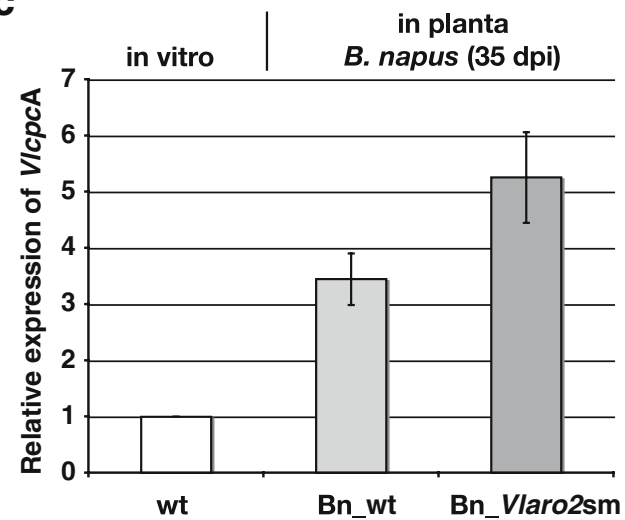

b

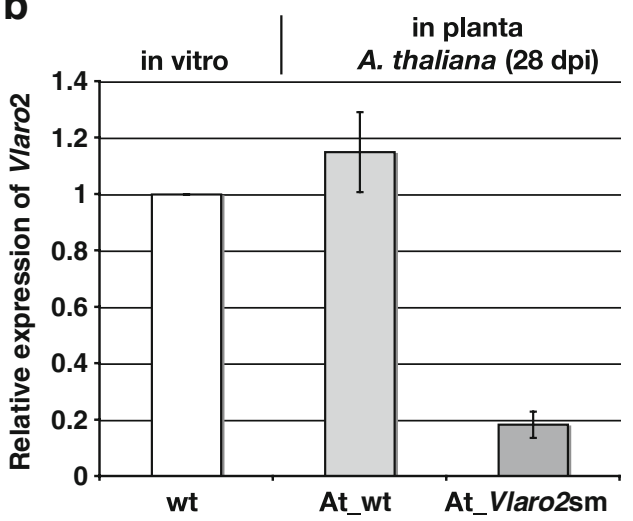

d

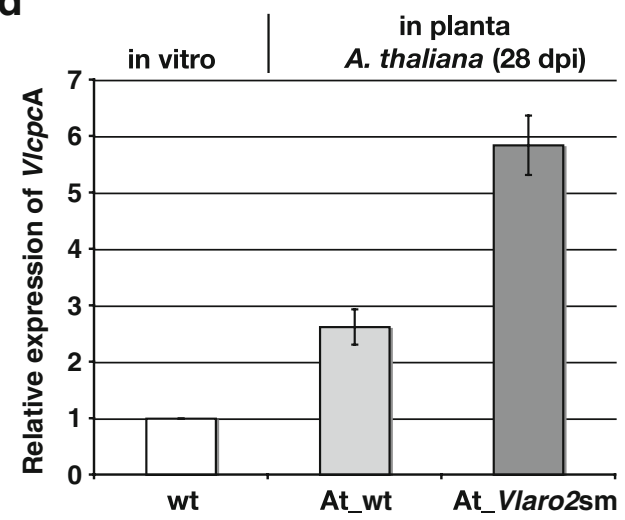

c Relative expression of $V l c p c A$ in $B$. napus measured by quantitative real-time PCR. VlcpcA cDNA was normalized to the $\beta$-tubulin cDNA. cDNA from host plants mock-inoculated with water served as control. $w t$, wild type, Bn_wt, cDNA from B. napus infected with wild type, Bn_Vlaro2sm, cDNA from B. napus infected with Vlaro2 silenced mutant. The error bars represent the standard deviations of triplicates. d Relative expression of VlcpcA in A. thaliana measured by quantitative real-time PCR. VlcpcA cDNA was normalized to the Btubulin cDNA. cDNA from host plants mock-inoculated with water served as control. $w t$, wild type, At_wt, cDNA from $A$. thaliana infected with wild type, At_Vlaro2sm, cDNA from A. thaliana infected with Vlaro 2 silenced mutant. The error bars represent the standard deviations of triplicates

1991). Auxotrophic mutants for V. longisporum CS would not have survived without supplementation of the culture medium by aromatic amino acids. Only the knockdown of Vlaro2 with a residual activity allowed the possibility to study the role of amino acids during biotrophic growth in the xylem.

Pathogenicity assays of the Vlaro2sm were not only performed in the host, B. napus but also in the model plant, A. thaliana. All Vlaro2sm-infected plants showed reduced stunting symptoms and disease scores. The reduced infection of host plants correlates to highly reduced growth of $V$. longisporum in planta. The successful usage of the $A$. thaliana model system might facilitate further studies, although the impact on the authentic host will be always ultimately necessary. 
The reduced rate of chorismate production in the bradytrophic mutant might also reduce the amount of secondary metabolites derived from aromatic amino acids. This could have an additional effect on the biotrophic lifestyle because secondary metabolites might help in propagation of the fungus in the host rapeseed plant. Aromatic amino-acid-derived secondary metabolites include auxins, melanin, or terrequinone A. The phytopathogenic fungi, Ustilago esculenta and Colletotrichum acutatum, can produce the plant hormone indole-3-acetic acid (IAA; auxin) efficiently from the aromatic amino acid tryptophan (Chung and Tzeng 2004; Lahey et al. 2004). A tomato isolate of $V$. albo-atrum produced IAA in CD medium (Pegg 1959). IAA production is also reported on a medium containing L-tryptophan by $V$. dahliae (Bhaskaran 1972). The enzymes in the shikimate pathway, chorismate mutase, and anthranilate synthetase have been described in the synthesis of IAA by V. albo-atrum (Pegg 1987). Auxins are known to stimulate the production of the gaseous plant hormone, ethylene (Arteca and Arteca 2008). Ethylene can inhibit growth of the plant stem and cause chlorosis, necrosis, and falling of leaves of the plant (Benavente and Alonso 2006). V. longisporum infection causes disease symptoms of stunting and early senescence in the rapeseed plants. It remains to be elucidated whether this is caused by generation of ethylene stimulated by auxin production by the fungus.

We further find that the expression of the gene for the major regulator of the cross-pathway control system is constitutively increased in $V$. longisporum during its growth in the xylem. The cross-pathway control is a complex global regulatory network, which regulates the synthesis of amino acids in numerous fungi. In the yeast $S$. cerevisiae, the same system had been named general control (Hinnebusch 1984; Natarajan et al. 2001). The crosspathway control has been studied in several filamentous fungi, including $A$. nidulans (Piotrowska 1980; Hoffmann et al. 2001), A. niger (Wanke et al. 1997), A. fumigatus (Krappmann et al. 2004), C. albicans (Tripathi et al. 2002), and N. crassa (Carsiotis et al. 1974; Paluh et al. 1988). Amino acid starvation conditions activate this system resulting in derepression of the cross-pathway control gene $G C N 4$ in yeast or $c p c A / c p c-1$ in filamentous fungi, respectively. Whereas in yeast there is primarily a translational control which determines the amount of Gen4 in the cell (Albrecht et al. 1998), there is an additional aminoacid-starvation-induced autoactivation present in filamentous fungi like $A$. nidulans (Hoffmann et al. 2001). In $V$. longisporum, we found that Vlaro2 silencing induced the expression of the gene for amino acid cross-pathway control, VlcpcA during saprotrophic life. This suggests that there is a similar autoactivation of VlcpcA as earlier described for A. nidulans $c p c A$. Consistently, VlcpcA was also induced under tryptophan starvation conditions in the wild type, corroborating that the fungus responds by increased VlcpcA expression to amino acid starvation. $V l c p c A$ was similarly induced in the wild type and in the Vlaro2sm during infection of $B$. napus and $A$. thaliana. This suggests that $A$. thaliana, which is much easier to study than B. napus, provides at least some similar signals to the fungus. We assume that the signal "amino acid starvation" is induced by the low and imbalanced levels of amino acids in the xylem vessels.

In addition to its role as amino acid regulator, the crosspathway control regulator $\mathrm{Gcn} 4 / \mathrm{CpcA} / \mathrm{Cpc}-1$ has various distinct morphological and pathogenic functions in fungi. Gen 4 controls starvation-induced adhesive growth in the yeast $S$. cerevisiae (Braus et al. 2003), which is required for pseudohyphal development. In A. nidulans, cross-pathway control is connected to cellular differentiation as increase in activity of the CpcA resulted in a reversible block of fruit body formation (Hoffmann et al. 2000). Histidine starvation in $C$. albicans induced morphogenetic responses dependent on the global regulator, CaGcn4 (Tripathi et al. 2002). In $A$. fumigatus, mutants impaired in cross-pathway control system had strongly reduced pathogenicity and CpcA seemed to be involved in establishing pulmonary aspergillosis effectively (Krappmann et al. 2004; Sasse et al. 2008). In V. longisporum, VlcpcA seems to aid in the growth of the fungus in the xylem vessels where amino acids are scarce. It will be interesting to see whether VlcpcA might have an additional important role in the establishment of the fungus in the host xylem vessels and subsequently in the pathogenicity of $V$. longisporum. The establishment of an efficient gene silencing system provided by this study is an essential prerequisite for the further analysis of this fungus and for the longstanding goal to control the biotrophic life phase efficiently.

Acknowledgements We are thankful to Prof. Dr. P. Macheroux (Institute of Biochemistry, Graz University of Technology, Austria) for providing us the Neurospora crassa CS antibody. We thank Dr. Sven Krappmann for helpful discussions. This work was supported by DFG research group grant FOR546.

Open Access This article is distributed under the terms of the Creative Commons Attribution Noncommercial License which permits any noncommercial use, distribution, and reproduction in any medium, provided the original author(s) and source are credited.

\section{References}

Albrecht G, Mösch HU, Hoffmann B, Reusser U, Braus GH (1998) Monitoring the Gcn4 protein mediated response in the yeast Saccharomyces cerevisiae. J Biol Chem 273:12696-12702

Arteca RN, Arteca JM (2008) Effects of brassinosteroid, auxin, and cytokinin on ethylene production in Arabidopsis thaliana plants. J Exp Bot 59:3019-3026 
Benavente LM, Alonso JM (2006) Molecular mechanisms of ethylene signaling in Arabidopsis. Mol Biosyst 2:165-173

Bentley R, Meganathan R (1982) Biosynthesis of vitamin K (menaquinone) in bacteria. Microbiol Rev 46:241-280

Bhaskaran R (1972) In vitro production of indole-3-acetic acid by Verticillium dahliae. Sci Cult 38:523

Bok JW, Hoffmeister D, Maggio-Hall LA, Murillo R, Glasner JD, Keller NP (2006) Genomic mining for Aspergillus natural products. Chem Biol 13:31-37

Braus GH (1991) Aromatic amino acid biosynthesis in the yeast Saccharomyces cerevisiae, a model system for the regulation of a eukaryotic biosynthetic pathway. Microbiol Rev 55:349-370

Braus GH, Grundmann O, Brückner S, Mösch HU (2003) Amino acid starvation and Gcn $4 p$ regulate adhesive growth and FLO11 gene expression in Saccharomyces cerevisiae. Mol Biol Cell 14:42724284

Braus GH, Pries R, Düvel K, Valerius O (2004) Molecular biology of fungal amino acid biosynthesis regulation. In: Kück U (ed) The Mycota II, genetics and biotechnology, 2nd edn. Springer, Heidelberg, pp 239-269

Burke D, Dawson D, Stearns T (2000) Methods in yeast genetics. Cold Spring Harbor Laboratory Press, New York

Carsiotis M, Jones RF, Wesseling AC (1974) Cross-pathway regulation, histidine-mediated control of histidine, tryptophan, and arginine biosynthetic enzymes in Neurospora crassa. J Bacteriol 119:893-898

Chung KR, Tzeng DD (2004) Biosynthesis of indole-3-acetic acid by the gall-inducing fungus Ustilago esculenta. J Biol Sci 4:17273048

Covert SF, Kapoor P, Lee M, Briley A, Nairn CJ (2001) Agrobacterium tumefaciens-mediated transformation of Fusarium circinatum. Mycol Res 105:259-264

de Jong JF, Deelstra HJ, Wösten HAB, Lugones LG (2006) RNA-mediated gene silencing in monokaryons and dikaryons of Schizophyllum commune. Appl Environ Microb 72:12671269

Draht OW, Busch S, Hofmann K, Braus-Stromeyer S, Helmstaedt K, Goldman GH, Braus GH (2008) Amino acid supply of Aspergillus. In: Goldmann GH, Osmani SA (eds) Mycology: the Aspergilli, vol 26. CRC, New York, pp 143-175

Eckert SE, Hoffmann B, Wanke C, Braus GH (1999) Sexual development of Aspergillus nidulans in tryptophan auxotrophic strains. Arch Microbiol 172:157-166

Ehammer H, Rauch G, Prem A, Kappes B, Macheroux P (2007) Conservation of NADPH utilization by chorismate synthase and, its implications for the evolution of the shikimate pathway. Mol Microbiol 65:1249-1257

Eynck C, Koopmann B, Grunewaldt-Stoecker G, Karlovsky P, von Tiedemann A (2007) Differential interactions of Verticillium longisporum and $V$. dahliae with Brassica napus detected with molecular and histological techniques. Eur J Plant Pathol 118:259-274

Fitzgerald A, Van Kan JA, Plummer KM (2004) Simultaneous silencing of multiple genes in the apple scab fungus, Venturia inaequalis, by expression of RNA with chimeric inverted repeats. Fungal Genet Biol 41:963-971

Hanahan D, Jessee J, Bloom FR (1991) Plasmid transformation of Escherichia coli and other bacteria. Methods Enzymol 204: $63-113$

Haslam E (1993) Shikimic acid, metabolism and metabolites. Wiley, New York

Heale JB, Karapapa VK (1999) The Verticillium threat to Canada's major oilseed crop, Canola. Can J Plant Pathol 21:1-7

Helmstaedt K, Krappmann S, Braus GH (2001) Allosteric regulation of catalytic activity: E. coli ATCase versus yeast chorismate mutase. Microbiol Mol Biol Rev 65:404-421
Henstrand JM, Schaller A, Braun M, Amrhein N, Schmid J (1996) Saccharomyces cerevisiae chorismate synthase has a flavin reductase activity. Mol Microbiol 22:859-866

Hinnebusch AG (1984) Evidence for translational regulation of the activator of general amino acid control in yeast. Proc Natl Acad Sci U S A 81:6442-6446

Hoffmann B, Wanke C, Kirchner SK, Braus GH (2000) c-Jun and $R A C K 1$ homologs regulate a control point for sexual development in Aspergillus nidulans. Mol Microbiol 37:28-41

Hoffmann B, Valerius O, Andermann M, Braus GH (2001) Transcriptional autoregulation and inhibition of mRNA translation of amino acid regulator gene $c p c A$ of filamentous fungus Aspergillus nidulans. Mol Biol Cell 12:2846-2857

Hsu AY, Do TQ, Lee PT, Clarke CF (2000) Genetic evidence for a multi-subunit complex in the $O$-methyltransferase steps of coenzyme Q biosynthesis. Biochim Biophys Acta 1484:287-297

Jones DG, Reusser U, Braus GH (1991) Molecular cloning, characterization and analysis of the regulation of the ARO2 gene, encoding chorismate synthase, of Saccharomyces cerevisiae. Mol Microbiol 5:2143-2152

Karapapa VK, Bainbridge BW, Heale JB (1997) Morphological and molecular characterization of Verticillium longisporum comb. nov., pathogenic to oilseed rape. Mycol Res 101:1281-1293

Kehr J, Buhtz A, Giavalisco P (2005) Analysis of xylem sap proteins from Brassica napus. BMC Plant Biol. doi:10.1186/1471-2229$5-11$

Kitzing K, Macheroux P, Amrhein N (2001) Spectroscopic and kinetic characterization of the bifunctional chorismate synthase from Neurospora crassa, evidence for a common binding site for 5enolpyruvylshikimate 3-phosphate and NADPH. J Biol Chem 276:42658-42666

Knaggs AR (2003) The biosynthesis of shikimate metabolites. Nat Prod Rep 20:119-136

Kolar M, Punt PJ, van den Hondel CA, Schwab H (1988) Transformation of Penicillium chrysogenum using dominant selection markers and expression of an Escherichia coli lacZ fusion gene. Gene 62:127-134

Krajaejun T, Gauthier GM, Rappleye CA, Sullivan TD, Klein BS (2007) Development and application of a green fluorescent protein sentinel system for identification of RNA interference in Blastomyces dermatitidis illuminates the role of septin in morphogenesis and sporulation. Eukaryot Cell 6:1299-1309

Krappmann S, Lipscomb WN, Braus GH (2000) Coevolution of transcriptional and allosteric regulation at the chorismate metabolic branch point of Saccharomyces cerevisiae. Proc Natl Acad Sci U S A 97:13585-13590

Krappmann S, Bignell EM, Reichard U, Rogers T, Haynes K, Braus GH (2004) The Aspergillus fumigatus transcriptional activator $\mathrm{CpcA}$ contributes significantly to the virulence of this fungal pathogen. Mol Microbiol 52:785-799

Künzler M, Paravicini G, Egli CM, Irniger S, Braus GH (1992) Cloning, primary structure and regulation of the ARO4 gene, encoding the tyrosine-inhibitable 3-deoxy-D-arabino-heptulosonate-7-phosphate synthase from Saccharomyces cerevisiae. Gene 113:67-74

Laemmli UK (1970) Cleavage of structural proteins during the assembly of the head of bacteriophage T4. Nature 227:680-685

Lahey KA, Yuan R, Burns JK, Ueng PP, Timmer LW, KuangRen C (2004) Induction of phytohormones and differential gene expression in citrus flowers infected by the fungus Colletotrichum acutatum. Mol Plant Microbe Interact 17: 1394-1401

Laxalt AM, Latijnhouwers M, van Hulten M, Govers F (2002) Differential expression of $G$ protein $\alpha$ and $\beta$ subunit genes during development of Phytophthora infestans. Fungal Genet Biol 36:137-146 
Lazo GR, Stein PA, Ludwig RA (1991) A DNA transformationcompetent Arabidopsis genomic library in Agrobacterium. Nat Biotechnol 9:963-967

Livak KJ, Schmittgen TD (2001) Analysis of relative gene expression data using real-time quantitative PCR and the $2^{-\Delta \Delta \mathrm{Ct}}$ method. Methods 25:402-408

Lopez-Millan AF, Morales F, Abadia A, Abadia J (2000) Effects of iron deficiency on the composition of the leaf apoplastic fluid and xylem sap in sugar beet. Implications for iron and carbon transport. Plant Physiol 124:873-884

Mannhaupt G, Stucka R, Pilz U, Schwarzlose C, Feldmann H (1989) Characterization of the prephenate dehydrogenase-encoding gene, TYR1, from Saccharomyces cerevisiae. Gene 85:303-311

Matityahu A, Hadar Y, Dosoretz CG, Belinky PA (2008) Gene silencing by RNA interference in the white rot fungus Phanerochaete chrysosporium. Appl Environ Microbiol 74:5359-5365

Miozzari G, Niederberger P, Hütter R (1978) Tryptophan biosynthesis in Saccharomyces cerevisiae, control of the flux through the pathway. J Bacteriol 134:48-59

Mouyna I, Henry C, Doering TL, Latge JP (2004) Gene silencing with RNA interference in the human pathogenic fungus Aspergillus fumigatus. FEMS Microbiol Lett 237:317-324

Mullins ED, Chen X, Romaine P, Raina R, Geiser DM, Kang S (2001) Agrobacterium-mediated transformation of Fusarium oxysporum: an efficient tool for insertional mutagenesis and gene transfer. Phytopathol 91:173-180

Nakayashiki H, Hanada S, Nguyen BQ, Kadotani N, Tosa Y, Mayama S (2005) RNA silencing as a tool for exploring gene function in ascomycete fungi. Fungal Genet Biol 42:275-283

Natarajan K, Meyer MR, Jackson BM, Slade D, Roberts C, Hinnebusch AG, Marton MJ (2001) Transcriptional profiling shows that Gen $4 p$ is a master regulator of gene expression during amino acid starvation in yeast. Mol Cell Biol 21:4347-4368

Paluh JL, Orbach MJ, Legerton TL, Yanofsky C (1988) The crosspathway control gene of Neurospora crassa, cpc-1, encodes a protein similar to GCN4 of yeast and the DNA-binding domain of the oncogene $v$-jun-encoded protein. Proc Natl Acad Sci U S A 85:3728-3732

Paravicini G, Mösch HU, Schmidheini T, Braus G (1989) The general control activator protein GCN4 is essential for a basal level of ARO3 gene expression in yeast. Mol Cell Biol 9:144-151

Panepinto JC, Oliver BG, Fortwendel JR, Smith DL, Askew DS, Rhodes JC (2003) Deletion of the Aspergillus fumigatus gene encoding the Ras-related protein RhbA reduces virulence in a model of invasive pulmonary aspergillosis. Infect Immun $71: 2819-2826$

Pegg GF (1959) Role of indole-3-acetic acid in the development of disease symptoms in Verticillium wilt of tomato. Proceedings of the Ninth International Botanical Congress. Montreal, Canada, p 297

Pegg GF (1987) Metabolism of IAA and its precursors by Verticillium albo-atrum and Verticillium-infected tomatoes. Can J Plant Pathol 9:84

Piotrowska M (1980) Cross-pathway regulation of ornithine carbamoyltransferase synthesis in Aspergillus nidulans. J Gen Microbiol 116:335-339

Quevillon-Cheruel S, Leulliot N, Meyer P, Graille M, Bremang M, Blondeau K, Sorel I, Poupon A, Janin J, van Tilbeurgh H (2004) Crystal structure of the bifunctional chorismate synthase from Saccharomyces cerevisiae. J Biol Chem 279:619-625
Riens B, Lohaus G, Heineke D, Heldt HW (1991) Amino acid and sucrose content determined in the cytosolic, chloroplastic, and vacuolar compartments and in the phloem sap of spinach leaves. Plant Physiol 97:227-233

Sambrook J, Fritsch EF, Maniatis T (1989) Molecular cloning. Cold Spring Harbor Laboratory Press, New York

Sasse C, Bignell EM, Hasenberg M, Haynes K, Gunzer M, Braus GH, Krappmann S (2008) Basal levels of the Aspergillus fumigatus transcriptional activator CpcA are sufficient to support pulmonary aspergillosis. Fungal Genet Biol 45:693-704

Satoh S, Kuroha T, Wakahoi T, Inouye Y (1998) Inhibition of the formation of adventitious roots on cucumber hypocotyls by the fractions and methoxybenzyl glutamine from xylem sap of squash root. J Plant Res 111:541-546

Satyanarayan V, Nair PM (1990) Metabolism, enzymology and possible roles of 4 aminobutyrate in higher plants. Phytochem 29:367-375

Schnathorst WC (1981) Life cycle and epidemiology of Verticillium. In: Mace ME, Bell AA, Beckmann CH (eds) Fungal wilt diseases of plants. Academic, New York, pp 81-111

Scholander PF, Bradstreet ED, Hemmingsen EA, Hammel HAT (1965) Sap pressure in vascular plants, negative hydrostatic pressure can be measured in plants. Science 148:339-346

Schuerch A, Miozzari J, Hütter R (1974) Regulation of tryptophan biosynthesis in Saccharomyces cerevisiae, mode of action of 5methyl-tryptophan and 5-methyl-tryptophan-sensitive mutants. J Bacteriol 117:1131-1140

Schurr U, Schulze ED (1995) The concentration of xylem sap constituents in root exudate, and in sap from intact, transpiring castor bean plants (Ricinus communis L.). Plant Cell Environ 18:409-420

Southern EM (1975) Detection of specific sequences among DNA fragments separated by gel electrophoresis. J Mol Biol 98:503-517

Tanguay P, Bozza S, Breuil C (2006) Assessing RNAi frequency and efficiency in Ophiostoma floccosum and O. piceae. Fungal Genet Biol 43:804-812

Teshiba S, Furter R, Niederberger P, Braus G, Paravicini G, Hütter R (1986) Cloning of the ARO3 gene of Saccharomyces cerevisiae and its regulation. Mol Gen Genet 205:353-357

Tilsner J, Kassner N, Struck C, Lohaus G (2005) Amino acid contents and transport in oilseed rape (Brassica napus L.) under different nitrogen conditions. Planta 221:328-338

Tripathi G, Wiltshire C, Macaskill S, Tournu H, Budge S, Brown AJ (2002) Gcn 4 co-ordinates morphogenetic and metabolic responses to amino acid starvation in Candida albicans. EMBO J 21:5448-5456

Wanke C, Eckert S, Albrecht G, van Hartingsveldt W, Punt PJ, van den Hondel CA, Braus GH (1997) The Aspergillus niger GCN4 homologue $c p c A$, is transcriptionally regulated and encodes an unusual leucine zipper. Mol Microbiol 23:23-33

Weiss U, Edwards JM (1980) The biosynthesis of aromatic compounds. Wiley, New York, pp 103-133

Williams PH, Hill CB (1986) Rapid-cycling populations of Brassica. Science 232:1385-1389

Zeise K, von Tiedemann A (2002) Application of RAPD-PCR for virulence type analysis within Verticillium dahliae and $V$. longisporum. J Phytopathol 150:557-563

Zhou L, Hu Q, Johansson A, Dixelius C (2006) Verticillium longisporum and $\mathrm{V}$. dahliae, infection and disease in Brassica napus. Plant Pathol 55:137-144

Zornoza P, Gonzalez M, Serrano S, Carpena O (1996) Intervarietal differences in xylem exudate composition and growth under contrasting forms of N supply in cucumber. Plant Soil 178:311-317 